NBER WORKING PAPER SERIES

\title{
CHANGES IN THE FEDERAL RESERVE'S INFLATION TARGET: CAUSES AND CONSEQUENCES
}

\author{
Peter N. Ireland \\ Working Paper 12492 \\ http://www.nber.org/papers/w12492 \\ NATIONAL BUREAU OF ECONOMIC RESEARCH \\ 1050 Massachusetts Avenue \\ Cambridge, MA 02138 \\ August 2006
}

All data and programs used in this research are freely available at http://www2.bc.edu/ irelandp. I would like to thank Paul Corrigan, Sharon Kozicki, Andre Kurmann, Stefan Laseen, Francesco Lippi, Jim Nason, Masao Ogaki, Louis Phaneuf, Tao Zha, and an anonymous referee, as well as seminar participants at the Bank of England, Boston University, Cornell University, the Federal Reserve Bank of Atlanta, the Federal Reserve Bank of Boston, the Federal Reserve Bank of Kansas City, the Federal Reserve Bank of St. Louis, the University of British Columbia, and the University of Illinois, for extremely helpful comments and suggestions and Suzanne Lorant for expert editorial assistance. Some of this work was completed while I was visiting the Research Department at the Federal Reserve Bank of Boston; I would like to thank the Bank and its staff for their hospitality and support. This material is also based upon work supported by the National Science Foundation under Grant No. SES-0213461. Any opinions, findings, and conclusions or recommedations expressed herein are my own and do not reflect those of the Federal Reserve Bank of Boston, the Federal Reserve System, the National Bureau of Economic Research, or the National Science Foundation.

(O2006 by Peter N. Ireland. All rights reserved. Short sections of text, not to exceed two paragraphs, may be quoted without explicit permission provided that full credit, including $\odot$ notice, is given to the source. 
Changes in the Federal Reserve's Inflation Target: Causes and Consequences

Peter N. Ireland

NBER Working Paper No. 12492

August 2006

JEL No. E31, E32, E52

\begin{abstract}
This paper estimates a New Keynesian model to draw inferences about the behavior of the Federal Reserve's unobserved inflation target. The results indicate that the target rose from $1 \frac{1 / 4}{4}$ percent in 1959 to over 8 percent in the mid-to-late 1970s before falling back below $2 \frac{1}{2}$ percent in 2004 . The results also provide some support for the hypothesis that over the entire postwar period, Federal Reserve policy has systematically translated short-run price pressures set off by supply-side shocks into more persistent movements in inflation itself, although considerable uncertainty remains about the true source of shifts in the inflation target.
\end{abstract}

Peter N. Ireland

Boston College

Department of Economics

Administration Building

140 Commonwealth Ave.

Chestnut Hill, MA 02467-3806

and NBER

irelandp@bc.edu 


\section{Introduction}

"Inflation is always and everywhere a monetary phenomenon." Thus spoke Milton Friedman (1968, p.39).

Once controversial, Friedman's words now form part of conventional wisdom for academic economists and central bankers alike, provided they are appropriately qualified as follows: transitory movements in the measured rate of inflation can be driven by shocks of various kinds, but large and persistent movements in inflation cannot occur without the help of monetary policy. Indeed, Friedman himself draws this distinction when defining (p.21) the "inflation" in his statement as a "steady and sustained rise in prices."

An interest rate rule for monetary policy of the type proposed by Taylor (1993) highlights exactly the same principles. Under the simplest such rule, the central bank adjusts the short-term nominal interest rate $r$ around its average or steady-state level $r^{*}$ in response to deviations of output $y$ and inflation $\pi$ from their target or steady-state levels $y^{*}$ and $\pi^{*}$ according to

$$
r=r^{*}+\omega_{y}\left(y-y^{*}\right)+\omega_{\pi}\left(\pi-\pi^{*}\right)
$$

where $\omega_{y}$ and $\omega_{\pi}$ are both positive coefficients. When it adopts such a rule, the central bank accepts responsibility for choosing the inflation target $\pi^{*}$ and for choosing a policy response coefficient $\omega_{\pi}$ that is large enough to stabilize the actual inflation rate $\pi$ around its target $\pi^{*}$. In the short run, movements in measured inflation $\pi$ may occur for many reasons, but in the long run, inflation remains tied down by monetary policy.

Nothing dictates that the central bank's inflation target must remain constant over time, however. In fact, Figure 1 shows that even in the relatively stable postwar U.S. economy, inflation exhibits large and persistent swings, trending upwards throughout the 1960s and 1970s before reversing course and falling during the 1980s and 1990s. Friedman's “always and everywhere" dictum strongly suggests that movements of the size and persistence seen in Figure 1 could not have taken place without ongoing shifts in the Federal Reserve's inflation 
target. But the Federal Reserve has never explicitly revealed the setting for its inflation target. Hence, a statistical or econometric model must be used to glean information about the Federal Reserve's inflation target from data on observable variables - that is, to disentangle those movements seen in Figure 1 that reflect shifts in the inflation target from those that are attributable to other types of shocks.

This paper develops such a model, drawing on contemporary macroeconomic theory to provide the identifying restrictions needed to shed light on the patterns, causes, and consequences of changes in the Federal Reserve's inflation target. The macroeconomic theory comes from a standard New Keynesian framework like those presented by Clarida, Gali, and Gertler (1999) and Woodford (2003) and used throughout much of the recent literature on monetary policy and the monetary business cycle. This model offers up a tight description, not just of Federal Reserve policy, but also of the optimizing behavior of the households and firms that populate the U.S. economy. Hence, estimates of the structural parameters of this simultaneous-equation model not only provide a detailed interpretation of historical movements in output, inflation, and interest rates as seen in the U.S. data, but also allow for an equally detailed consideration of counterfactual scenarios such as: what would the behavior of these variables have looked like if, instead, the Federal Reserve had maintained a constant inflation target throughout the postwar period?

Blinder (1982), Hetzel (1998), and Mayer (1998) all attribute the upward secular trend in inflation shown in Figure 1 for the period before 1980 to a systematic tendency for Federal Reserve policy to translate the short-run price pressures set off by adverse supply shocks into more persistent movements in the inflation rate itself - part of an effort by policymakers to avoid at least some of the contractionary impact those shocks would otherwise have had on the real economy. Symmetrically, Bomfim and Rudebusch (2000) and Orphanides and Wilcox (2002) suggest that at times during the post-1980 period, the Federal Reserve took advantage of favorable supply-side disturbances to "opportunistically" work the inflation rate back down. To capture these ideas, the model developed here includes a generalized Taylor 
rule that allows the Federal Reserve's inflation target to respond systematically to shocks hitting the economy from the supply side. The estimation results provide some support for a unified version of these stories that applies to the entire postwar period, although the same results also indicate that considerable uncertainty remains as to exactly why the Federal Reserve allowed inflation to move as much as it did.

Before going on to provide a more detailed description of the model and results, mention should be made of three related sets of contributions to the recent literature. First, Kozicki and Tinsley (2001), Rudebusch and Wu (2004), Gurkaynak, Sack, and Swanson (2005), and Dewachter and Lyrio (2006) argue that the behavior of both short- and long-term interest rates in the U.S. data becomes easier to reconcile with the expectations hypothesis of the term structure if one allows for shifts in the long-run inflation rate. Thus, these previous studies help motivate the analysis performed here, which focuses solely on macroeconomic variables in an effort to estimate more sharply exactly when those shifts took place and why.

Second, Erceg and Levin (2003), Smets and Wouters (2003), Roberts (2004), Cogley and Sbordone (2005), Gavin, Keen, and Pakko (2005), and Salemi (2005) also develop macroeconomic models that allow for continual movement in the Federal Reserve's inflation target. However, each of these previous studies focuses on a different set of issues: Erceg and Levin (2003), on private agents' inability to disentangle transitory from persistent movements in the inflation target and the role that this incomplete information plays in accounting for the inflationary dynamics observed during the Volcker disinflation in the United States; Smets and Wouters (2003), on the ability of their larger-scale New Keynesian model to track the postwar U.S. data on an expanded number of variables both in and out of sample; Roberts (2004), on the ability of his model to capture the changing relationships between U.S. unemployment and inflation since 1980; Cogley and Sbordone (2005), on the stability of the estimated parameters of a Phillips curve relationship in the face of changes elsewhere in the economy; Gavin, Keen, and Pakko (2005), on the ability of their model to account for the persistence of inflation and the relative volatilities of money growth and inflation in the post- 
1980 U.S. data; and Salemi (2005), on the relative weights placed by the Federal Reserve on its stabilization objectives for output, inflation, and interest rates over the postwar period. Thus, none of these previous studies focuses as this paper does on obtaining estimates of the Federal Reserve's continually-changing inflation target; and none of these previous studies attempts as this paper does to model specifically those target changes as deliberate policy responses to other shocks that have hit the economy, in order to tie together the stories told earlier by Blinder (1982), Hetzel (1998), and Mayer (1998) on the one hand and Bomfim and Rudebusch (2000) and Orphanides and Wilcox (2002) on the other.

Third and finally, in work that relates most closely to the present study, Kozicki and Tinsley (2005) develop an empirical model - a generalized vector autoregression — that allows for changes in the Federal Reserve's inflation target that are imperfectly perceived by private agents and that reflect, in part, the response of the central bank to supply shocks that have hit the U.S. economy over the postwar period. But whereas Kozicki and Tinsley focus on the differing responses of the economy to shocks of various kinds as implied by their generalized model versus a more conventional vector autoregression that assumes a constant inflation target and full information possessed by private agents, the focus here, again, lies in characterizing more sharply the nature and sources of variation in the Federal Reserve's inflation target itself and linking the econometric results to the earlier accounts of Blinder (1982), Hetzel (1998), Mayer (1998), Bomfim and Rudebusch (2000) and Orphanides and

Wilcox (2002). The analysis presented here also extends and complements Kozicki and Tinsley's earlier work by imposing more structure on the data, fully exploiting the behavioral relationships implied by the New Keynesian model.

\section{The Model}

The model developed here shares its basic features with many recent New Keynesian formulations, including the benchmark models of Clarida, Gali, and Gertler (1999) and Woodford 
(2003), but resembles most closely the specification used in Ireland (2004a). As noted above, one extension to previous models that appears for the first time here is a generalized Taylor (1993) rule for monetary policy that allows the central bank's inflation target to adjust in response to other shocks that hit the economy. Indeed, the use of this tightly parameterized structural model, as opposed to a more loosely constrained vector autoregression or unobserved components model, allows for the simultaneous identification not just of movements in the inflation target but also of the exogenous supply-side disturbances that, according to Blinder (1982), Hetzel (1998), and Mayer (1998), prompted the Federal Reserve to accommodate higher and higher rates of inflation throughout the 1960s and 1970s. And, again, as noted above, the use of this tightly parameterized structural model responds to the Lucas (1976) critique, allowing for a detailed consideration of the counterfactual scenario in which, instead, the Federal Reserve held the line on inflation in the face of those shocks.

The model economy consists of a representative household, a representative finishedgoods-producing firm, a continuum of intermediate-goods-producing firms indexed by $i \in$ $[0,1]$, and a central bank. During each period $t=0,1,2, \ldots$, each intermediate-goodsproducing firm manufactures a distinct, perishable intermediate good. Hence, intermediate goods may also be indexed by $i \in[0,1]$, where firm $i$ produces good $i$. The model retains enough symmetry, however, to allow the analysis to focus on the activities of a representative intermediate-goods-producing firm, which produces the generic intermediate good $i$. Thus, a description of the model boils down to a description of the optimizing behavior of the three representative private agents - the household, the finished-goods-producing firm, and the intermediate-goods-producing firm - together with a description of the generalized Taylor rule adopted by the central bank.

The representative household enters each period $t=0,1,2, \ldots$ with money $M_{t-1}$ and bonds $B_{t-1}$. At the beginning of the period, the household receives a lump-sum nominal transfer $T_{t}$ from the central bank. Next, the household's bonds mature, throwing off $B_{t-1}$ additional units of money. The household uses some of this money to purchase $B_{t}$ new bonds 
at the price of $1 / R_{t}$ units of money per bond, where $R_{t}$ denotes the gross nominal interest rate between $t$ and $t+1$. During the period, the household supplies a total of $h_{t}$ units of labor to the various intermediate-goods-producing firms and gets paid at the nominal wage rate $W_{t}$. Also during the period, the household consumes $C_{t}$ units of the finished good, purchased at the nominal price $P_{t}$ from the representative finished-goods-producing firm. At the end the period, the household receives nominal profits $D_{t}$ in the form of dividends paid by the intermediate-goods-producing firms. The household then carries $M_{t}$ units of money into period $t+1$; its budget constraint requires that

$$
M_{t-1}+T_{t}+B_{t-1}+W_{t} h_{t}+D_{t} \geq P_{t} C_{t}+M_{t}+B_{t} / R_{t}
$$

for all $t=0,1,2, \ldots$

Facing the budget constraint (1), the household chooses $C_{t}, h_{t}, B_{t}$, and $M_{t}$ for all $t=$ $0,1,2, \ldots$ to maximize the expected utility function

$$
E_{0} \sum_{t=0}^{\infty} \beta^{t} a_{t}\left[\ln \left(C_{t}-\gamma C_{t-1}\right)+\ln \left(M_{t} / P_{t}\right)-h_{t}\right]
$$

where the discount factor $\beta$ and the habit formation parameter $\gamma$ both lie between zero and one: $1>\beta>0$ and $1 \geq \gamma \geq 0$. The preference shock $a_{t}$ follows the stationary autoregressive process

$$
\ln \left(a_{t}\right)=\rho_{a} \ln \left(a_{t-1}\right)+\sigma_{a} \varepsilon_{a t}
$$

for all $t=0,1,2, \ldots$, with $1>\rho_{a} \geq 0$ and $\sigma_{a} \geq 0$, where the serially uncorrelated innovation $\varepsilon_{a t}$ has the standard normal distribution. Utility is additively separable in consumption, real money balances, and hours worked; as shown by Driscoll (2000) and Ireland (2004b), this additive separability is needed to derive a conventional specification for the model's IS relationship that, in particular, excludes terms involving money and employment. Given this additive separability, the logarithmic specification for utility from consumption is needed, as 
shown by King, Plosser, and Rebelo (1988), for the model to remain consistent with balanced growth. Finally, habit formation is introduced into preferences following Fuhrer (2000), who shows that this feature - and the partially backward-looking consumption it implies - helps New Keynesian models like this one replicate the observed effects on real spending of shocks of various kinds.

The representative finished-goods-producing firm uses $Y_{t}(i)$ units of each intermediate good $i \in[0,1]$, purchased at the nominal price $P_{t}(i)$ during each period $t=0,1,2, \ldots$, to manufacture $Y_{t}$ units of the finished good according to the constant-returns-to-scale technology described by

$$
\left[\int_{0}^{1} Y_{t}(i)^{\left(\theta_{t}-1\right) / \theta_{t}} d i\right]^{\theta_{t} /\left(\theta_{t}-1\right)} \geq Y_{t}
$$

where $\theta_{t}$ follows the stationary autoregressive process

$$
\ln \left(\theta_{t}\right)=\left(1-\rho_{\theta}\right) \ln (\theta)+\rho_{\theta} \ln \left(\theta_{t-1}\right)+\sigma_{\theta} \varepsilon_{\theta t}
$$

for all $t=0,1,2, \ldots$, with $1>\rho_{\theta} \geq 0$ and $\sigma_{\theta} \geq 0$, and where the serially uncorrelated innovation $\varepsilon_{\theta t}$ has the standard normal distribution. The firm acts to maximize its profits; the first-order conditions for this problem are

$$
Y_{t}(i)=\left[P_{t}(i) / P_{t}\right]^{-\theta_{t}} Y_{t}
$$

for all $i \in[0,1]$ and $t=0,1,2, \ldots$

These optimality conditions reveal that $-\theta_{t}$ measures the time-varying elasticity of demand for each intermediate good $i \in[0,1]$. Hence, as in Smets and Wouters (2003), Steinsson (2003), and Ireland (2004a), random shocks to $\theta_{t}$ translate into shocks to the intermediategoods-producing firms' desired markups of price over marginal cost; in equilibrium, they act like cost-push shocks of the kind introduced into the New Keynesian model by Clarida, Gali, and Gertler (1999). Competition drives the finished-goods-producing firm's profits to zero 
in equilibrium, determining $P_{t}$ as

$$
P_{t}=\left[\int_{0}^{1} P_{t}(i)^{1-\theta_{t}} d i\right]^{1 /\left(1-\theta_{t}\right)}
$$

for all $t=0,1,2, \ldots$

The representative intermediate-goods-producing firm hires $h_{t}(i)$ units of labor from the representative household during each period $t=0,1,2, \ldots$ to manufacture $Y_{t}(i)$ units of intermediate good $i$ according to the constant-returns-to-scale technology described by

$$
Z_{t} h_{t}(i) \geq Y_{t}(i)
$$

The aggregate technology shock follows a random walk with drift:

$$
\ln \left(Z_{t}\right)=\ln (z)+\ln \left(Z_{t-1}\right)+\sigma_{z} \varepsilon_{z t}
$$

for all $t=0,1,2, \ldots$, with $z>1$ and $\sigma_{z} \geq 0$, where the serially uncorrelated innovation $\varepsilon_{z t}$ has the standard normal distribution. This random walk assumption for the technology shock serves to distinguish its effects from those of the cost-push shock: as supply-side disturbances, both shocks tend to move output and inflation in opposite directions in the short run, but only the technology shock has permanent effects on the level of output.

Since the intermediate goods substitute imperfectly for one another in producing the finished good, the representative intermediate-goods-producing firm sells its output in a monopolistically competitive market: during period $t$, the firm sets the nominal price $P_{t}(i)$ for its output, subject to the requirement that it satisfy the representative finished-goods-producing firm's demand at that chosen price. And, as in Rotemberg (1982), the intermediate-goodsproducing firm faces a quadratic cost of adjusting its price between periods, measured in 
terms of the finished good and given by

$$
\frac{\phi}{2}\left[\frac{P_{t}(i)}{\prod_{t-1}^{\alpha}\left(\Pi_{t}^{*}\right)^{1-\alpha} P_{t-1}(i)}-1\right]^{2} Y_{t}
$$

where $\phi \geq 0$ governs the magnitude of the adjustment cost, $\Pi_{t}=P_{t} / P_{t-1}$ so that $\Pi_{t-1}$ denotes the gross inflation rate between periods $t-2$ and $t-1$, $\Pi_{t}^{*}$ denotes the central bank's inflation target for period $t$, and the parameter $\alpha$ lies between zero and one: $1 \geq \alpha \geq 0$. According to this specification, the extent to which price setting is backward instead of forward looking depends on how close $\alpha$ is to one. In particular, as shown below, when $\alpha=0$ so that firms find it costless to adjust their prices in line with the central bank's inflation target, the model's Phillips curve relation becomes purely forward looking. At the opposite extreme, when $\alpha=1$ so that firms find it costless to adjust their prices in line with the previous period's inflation rate, the backward-looking term in the Phillips curve becomes approximately equal in importance to the forward-looking term, as in Fuhrer and Moore's $(1995 a, 1995 b)$ framework. In any case, the cost of price adjustment makes the intermediate-goods-producing firm's problem dynamic: it chooses $P_{t}(i)$ for all $t=0,1,2, \ldots$ to maximize its total market value, as described below in Appendix A.

The central bank conducts monetary policy according to the generalized Taylor (1993) rule

$$
\ln \left(R_{t}\right)-\ln \left(R_{t-1}\right)=\rho_{\pi} \ln \left(\Pi_{t} / \Pi_{t}^{*}\right)+\rho_{g y} \ln \left(g_{t}^{y} / g^{y}\right)+\ln \left(v_{t}\right)
$$

for all $t=0,1,2 \ldots$, where the response coefficients $\rho_{\pi}>0$ and $\rho_{g y} \geq 0$ are chosen by the central bank. Here, as in Fuhrer and Moore (1995b), the central bank increases the short-term nominal interest rate $R_{t}$ whenever the inflation rate rises above its target $\Pi_{t}^{*}$; a strictly positive value for $\rho_{\pi}$ helps provide for the existence of a unique rational expectations equilibrium under an interest rate rule of this type. Since the level of output $Y_{t}$ inherits a unit root from the random walk process (6) for the technology shock $Z_{t},(7)$ dictates that 
the central bank respond instead to the growth rate of output

$$
g_{t}^{y}=Y_{t} / Y_{t-1}
$$

as a stationary measure of real economic activity, increasing the short-term nominal interest rate whenever growth output growth rises above its steady-state level $g^{y}=z$. The transitory monetary policy shock $v_{t}$ in (7) follows the stationary autoregressive process

$$
\ln \left(v_{t}\right)=\rho_{v} \ln \left(v_{t-1}\right)+\sigma_{v} \varepsilon_{v t}
$$

for all $t=0,1,2, \ldots$, with $1>\rho_{v} \geq 0$ and $\sigma_{v} \geq 0$, where the serially uncorrelated innovation $\varepsilon_{v t}$ has the standard normal distribution.

As noted above, a novel feature of the generalized Taylor rule (7) incorporated into this model is the time-varying inflation target $\Pi_{t}^{*}$, which evolves according to

$$
\ln \left(\Pi_{t}^{*}\right)=\ln \left(\Pi_{t-1}^{*}\right)-\delta_{\theta} \varepsilon_{\theta t}-\delta_{z} \varepsilon_{z t}+\sigma_{\pi} \varepsilon_{\pi t}
$$

for all $t=0,1,2, \ldots$, where the response coefficients $\delta_{\theta} \geq 0$ and $\delta_{z} \geq 0$ are again chosen by the central bank, where $\sigma_{\pi} \geq 0$, and where the serially uncorrelated innovation $\varepsilon_{\pi t}$ has the standard normal distribution. This addition to the Taylor rule allows the inflation target to vary exogenously when $\sigma_{\pi}$ is strictly positive and also allows the central bank to systematically adjust its inflation target in response to either or both of the two supply shocks: the cost-push shock $\theta_{t}$ and the technology shock $Z_{t}$. Since adverse supply shocks (negative realizations of $\varepsilon_{\theta t}$ and $\varepsilon_{z t}$ ) work to increase goods' prices, and favorable supply shocks (positive realizations of $\varepsilon_{\theta t}$ and $\varepsilon_{z t}$ ) work to decrease goods' prices, strictly positive values for $\delta_{\theta}$ and $\delta_{z}$ help the model bring together and formalize the stories told by Blinder (1982), Hetzel (1998), Mayer (1998), Bomfim and Rudebusch (2000), and Orphanides and Wilcox (2002), according to which the Federal Reserve acted systematically over the postwar 
period to translate the short-run price pressures set off by these shocks into more persistent movements in the inflation rate itself.

Finally, the random walk specification for the inflation target that is built into (10) represents an identifying assumption that, in very much the same spirit as the random walk assumption (6) for technology, helps to distinguish the effects of changes in the inflation target from those generated by the model's other four shocks. This identifying assumption, motivated by Friedman's (1968) "always and everywhere" dictum, can be stated more simply as: permanent changes in measured inflation $\Pi_{t}$ cannot occur without corresponding changes in the central bank's inflation target $\Pi_{t}^{*}$.

Preliminary econometric analysis of this New Keynesian model allowed the central bank, through an expanded version of the Taylor rule (7), to adjust the short-term nominal interest rate not only in response to movements in inflation and output growth, but also in response to movements in a welfare-theoretic measure of the output gap, defined below in Appendix B as the deviation of actual equilibrium output from its efficient, or Pareto optimal, level. As well, preliminary analysis allowed the central bank, through an expanded version of (10), to adjust its inflation target not only in response to the cost-push and technology shocks, but also in response to the preference shock. Inevitably, however, the estimation routine pushed the associated response coefficients towards zero, and so, for simplicity, these additional variables were dropped from the final specification used here.

In a symmetric equilibrium, all intermediate-goods-producing firms make identical decisions, so that $Y_{t}(i)=Y_{t}, h_{t}(i)=h_{t}$, and $P_{t}(i)=P_{t}$ for all $i \in[0,1]$ and $t=0,1,2, \ldots$ In addition, the market-clearing conditions for money and bonds, $M_{t}=M_{t-1}+T_{t}$ and $B_{t}=B_{t-1}=0$ must hold for all $t=0,1,2, \ldots$. The real variables $Y_{t}$ and $C_{t}$ inherit unit roots from the process (6) for technology, as does $\Lambda_{t}$, defined in Appendix A as the Lagrange multiplier on the budget constraint (1) from the representative household's problem. However, the transformed variables $y_{t}=Y_{t} / Z_{t}, c_{t}=Y_{t} / Z_{t}, \lambda_{t}=Z_{t} \Lambda_{t}$, and $z_{t}=Z_{t} / Z_{t-1}$ all remain stationary, as does the output growth rate $g_{t}^{y}$. Similarly, the nominal variables $\Pi_{t}$ and $R_{t}$ 
inherit unit roots from the process (10) for the inflation target $\Pi_{t}^{*}$; however, the transformed variables $\pi_{t}=\Pi_{t} / \Pi_{t}^{*}, r_{t}=R_{t} / \Pi_{t}^{*}$, and $\pi_{t}^{*}=\Pi_{t}^{*} / \Pi_{t-1}^{*}$ remain stationary, as do the growth rate of inflation

$$
g_{t}^{\pi}=\Pi_{t} / \Pi_{t-1}
$$

and the ratio of the nominal interest rate to the inflation rate

$$
r_{t}^{r \pi}=R_{t} / \Pi_{t}
$$

Appendix A lists the model's equilibrium conditions, including the first-order conditions describing the optimizing behavior of the representative household and intermediate-goodsproducing firm. When rewritten in terms of the model's stationary variables, these conditions imply that in the absence of shocks, the economy converges to a steady-state growth path, along which $y_{t}=y=[(\theta-1) / \theta][(z-\beta \gamma) /(z-\gamma)], c_{t}=c=[(\theta-1) / \theta][(z-\beta \gamma) /(z-\gamma)]$, $\pi_{t}=1, r_{t}=r=z / \beta, g_{t}^{y}=g^{y}=z, g_{t}^{\pi}=1, r_{t}^{r \pi}=r^{r \pi}=z / \beta, \lambda_{t}=\lambda=\theta /(\theta-1), a_{t}=1$, $\theta_{t}=\theta, z_{t}=z, v_{t}=1$, and $\pi_{t}^{*}=1$ for all $t=0,1,2, \ldots$. The stationary system can therefore be log-linearized around its steady state to describe how the economy responds to shocks. Let $\hat{y}_{t}=\ln \left(y_{t} / y\right), \hat{c}_{t}=\ln \left(c_{t} / c\right), \hat{\pi}_{t}=\ln \left(\pi_{t}\right), \hat{r}_{t}=\ln \left(r_{t} / r\right), \hat{g}_{t}^{y}=\ln \left(g_{t}^{y} / g^{y}\right)$, $\hat{g}_{t}^{\pi}=\ln \left(g_{t}^{\pi}\right), \hat{r}_{t}^{r \pi}=\ln \left(r_{t}^{r \pi} / r^{r \pi}\right), \hat{\lambda}_{t}=\ln \left(\lambda_{t} / \lambda\right), \hat{a}_{t}=\ln \left(a_{t}\right), \hat{\theta}_{t}=\ln \left(\theta_{t} / \theta\right), \hat{z}_{t}=\ln \left(z_{t} / z\right)$, $\hat{v}_{t}=\ln \left(v_{t}\right)$, and $\hat{\pi}_{t}^{*}=\ln \left(\pi_{t}^{*}\right)$ measure the percentage deviation of each stationary variable from its steady-state level. A first-order Taylor approximation to the economy's aggregate resource constraint implies that $\hat{c}_{t}=\hat{y}_{t}$ : price adjustment costs are of second-order importance around the steady state growth path. First-order approximations to the remaining equilibrium conditions equations then imply

$$
\begin{gathered}
(z-\gamma)(z-\beta \gamma) \hat{\lambda}_{t}=\gamma z \hat{y}_{t-1}-\left(z^{2}+\beta \gamma^{2}\right) \hat{y}_{t}+\beta \gamma z E_{t} \hat{y}_{t+1}+(z-\gamma)\left(z-\beta \gamma \rho_{a}\right) \hat{a}_{t}-\gamma z \hat{z}_{t} \\
\hat{\lambda}_{t}=E_{t} \hat{\lambda}_{t+1}+\hat{r}_{t}-E_{t} \hat{\pi}_{t+1}
\end{gathered}
$$




$$
\begin{gathered}
(1+\beta \alpha) \hat{\pi}_{t}=\alpha \hat{\pi}_{t-1}+\beta E_{t} \hat{\pi}_{t+1}+\psi\left(\hat{a}_{t}-\hat{\lambda}_{t}\right)-\hat{e}_{t}-\alpha \hat{\pi}_{t}^{*}, \\
\hat{r}_{t}-\hat{r}_{t-1}=\rho_{\pi} \hat{\pi}_{t}+\rho_{g y} \hat{g}_{t}^{y}-\hat{\pi}_{t}^{*}+\hat{v}_{t} \\
\hat{\pi}_{t}^{*}=\sigma_{\pi} \varepsilon_{\pi t}-\delta_{e} \varepsilon_{e t}-\delta_{z} \varepsilon_{z t}, \\
\hat{g}_{t}^{y}=\hat{y}_{t}-\hat{y}_{t-1}+\hat{z}_{t} \\
\hat{g}_{t}^{\pi}=\hat{\pi}_{t}-\hat{\pi}_{t-1}+\hat{\pi}_{t}^{*} \\
\hat{r}_{t}^{r \pi}=\hat{r}_{t}-\hat{\pi}_{t} \\
\hat{a}_{t}=\rho_{a} \hat{a}_{t-1}+\sigma_{a} \varepsilon_{a t}, \\
\hat{e}_{t}=\rho_{e} \hat{e}_{t-1}+\sigma_{e} \varepsilon_{e t} \\
\hat{z}_{t}=\sigma_{z} \varepsilon_{z t},
\end{gathered}
$$

and

$$
\hat{v}_{t}=\rho_{v} \hat{v}_{t-1}+\sigma_{v} \varepsilon_{v t}
$$

for all $t=0,1,2, \ldots$, where, in $(15),(17)$, and (22), the cost-push shock $\hat{\theta}_{t}$ has been renormalized as $\hat{e}_{t}=(1 / \phi) \hat{\theta}_{t}$, and the new parameters $\psi, \delta_{e}, \rho_{e}$, and $\sigma_{e}$ have been defined as $\psi=(\theta-1) / \phi, \delta_{e}=\delta_{\theta}, \rho_{e}=\rho_{\theta}$, and $\sigma_{e}=\sigma_{\theta} / \phi$, so that, like $\varepsilon_{\theta t}, \varepsilon_{e t}$ has the standard normal distribution.

Since (18)-(20) simply restate the definitions of the output growth rate $\hat{g}_{t}^{y}$, the inflation growth rate $\hat{g}_{t}^{\pi}$, and the ratio of the nominal interest rate to the inflation rate $\hat{r}_{t}^{r \pi}$ and since (21)-(24) simply describe the processes for the exogenous preference, cost-push, technology, and monetary policy shocks, the model's economic content is concentrated in (13)-(17). In particular, (14) takes the form of a New Keynesian IS curve linking the marginal utility of consumption during period $t$ to its own expected future value and to the value of the $e x$ ante real interest rate, while (13) measures the marginal utility of consumption and includes both forward- and backward-looking terms based on the habit formation specification for 
preferences. Equation (15) takes the form of a hybrid forward- and backward-looking New Keynesian Phillips curve, with the parameter $\alpha$ from the price adjustment cost formulation indexing the degree of backward-looking behavior, the parameter $\psi$ multiplying the real marginal cost term $\hat{a}_{t}-\hat{\lambda}_{t}$, and the cost-push shock $\hat{e}_{t}$ entering additively. In particular and as noted above, (15) reveals that when $\alpha=0$, the model's Phillips curve relationship becomes purely forward looking, in the sense that the term involving lagged inflation $\hat{\pi}_{t-1}$ drops out of the specification; when $\alpha=1$, on the other hand, the model's Phillips curve resembles Fuhrer and Moore's $(1995 a, 1995 b)$, in the sense that the forward- and backwardlooking terms $E_{t} \hat{\pi}_{t+1}$ and $\hat{\pi}_{t-1}$ receive approximately equal weights. Finally, (16) and (17) describe the conduct of monetary policy, including the possibly endogenous evolution of the central bank's inflation target as well as the Taylor-type adjustment of the nominal interest rate taken to stabilize actual inflation around its target.

\section{Empirical Strategy and Results}

Blanchard and Kahn (1980) and Klein (2000) describe methods for solving systems of linearized expectational difference equations such as (13)-(24). These methods provide solutions that quite conveniently take the same form as a state-space econometric model: in this case, the solution links the behavior of the stationary model's three observable variables - the growth rate of output $\hat{g}_{t}^{y}$, the growth rate of inflation $\hat{g}_{t}^{\pi}$, and the ratio of the nominal interest rate to the inflation rate $\hat{r}_{t}^{r \pi}$ - to the remaining, unobservable variables. Hence, the Kalman filtering algorithms outlined by Hamilton (1994, Ch.13) can be applied to obtain maximum likelihood estimates of the model's structural parameters and to optimally exploit information contained in the observable data to draw inferences about the behavior of the unobservables including, most importantly, the unobservable inflation target $\hat{\pi}_{t}^{*}$.

Here, this econometric exercise uses quarterly U.S. data running from 1959:1 through 2004:2. In these data, readings on seasonally-adjusted real gross domestic product in chained 
2000 dollars, expressed in per-capita terms by dividing by the civilian noninstitutional population, age 16 and over, provide the measure of output $Y_{t}$. Readings on the seasonallyadjusted GDP implicit price deflator provide the measure of the nominal price level $P_{t}$, and readings on the three-month U.S. Treasury bill provide the measure of the short-term nominal interest rate $R_{t}$. Prior to their use in the estimation exercise, these raw series get passed through the same stationary-inducing transformations required to solve the theoretical model. Hence, the empirical model assumes that all three series contain unit roots but that the inflation and interest rates are cointegrated so that, again, the growth rate of output, the growth rate of inflation, and the ratio of the nominal interest rate to the inflation rate are the most relevant stationary variables.

Under the additional assumption that the innovations $\varepsilon_{a t}, \varepsilon_{e t}, \varepsilon_{z t}, \varepsilon_{v t}$, and $\varepsilon_{\pi t}$ are mutually as well as serially uncorrelated, the model has 17 parameters: $z, \beta, \psi, \gamma, \alpha, \rho_{\pi}, \rho_{g y}$, $\rho_{a}, \rho_{e}, \rho_{v}, \sigma_{a}, \sigma_{e}, \sigma_{z}, \sigma_{v}, \sigma_{\pi}, \delta_{e}$, and $\delta_{z}$. Values $z=1.0047$ and $\beta=0.9995$ for the first two parameters on this list of fixed prior to estimation in order to insure that the steady-state rate of output growth $g^{y}=z$ and the steady-state ratio of the nominal interest rate to the inflation rate $r^{r \pi}=z / \beta$ as implied by the theoretical model match the average values of the same two variables as measured in the data. The model implies that along the steady-state growth path, the growth rate of inflation is zero and, indeed, in the U.S. data, the sample average of the growth rate of inflation is quite small: Figure 1 reveals that, in levels, the inflation rate ends the 45-year sample period at approximately the same point at which it begins, so that the average quarterly rate of change in inflation over four-and-a-half decades is only 0.000016 , that is, 0.0016 of one percent or 0.16 basis points. Hence, all variables are accurately de-meaned prior to estimation, again in a manner consistent with the implications of the theoretical model.

Preliminary attempts to estimate the model's remaining 15 parameters consistently led to very small values of $\psi$, the coefficient on real marginal cost in the Phillips curve (15); since $\psi=(\theta-1) / \phi$, these small values for $\psi$ correspond to very large values for the price 
adjustment cost parameter $\phi$. Hence, in deriving the results described below, the same setting $\psi=0.10$ used in Ireland $(2004 a, 2004 b)$ is also imposed prior to estimation. The formulas displayed by Gali and Gertler (1999, p.211) provide a convenient way of interpreting this setting for $\psi$ : in a model in which firms set prices in a staggered fashion according to Calvo's (1983) formulation instead of facing an explicit cost of price adjustment as they do here, a value of $\psi=0.10$ for the coefficient on the real marginal cost term in a purely forward-looking New Keynesian Phillips curve implies that individual goods prices remain fixed, on average, for 3.7 quarters - or just under one year.

With these three parameter values fixed in advance, Table 1 presents maximum likelihood estimates of the model's remaining parameters. The standard errors, also shown in Table 1, come from a parametric bootstrapping procedure similar to those used by Malley, Philippopoulos, and Woitek (2005) and Cho and Moreno (2006) and described in more detail by Efron and Tibshirani (1993, Ch.6). This procedure simulates the estimated model in order to generate 1,000 samples of artificial data for the growth rate of output, the growth rate of inflation, and the ratio of the nominal interest rate to the inflation rate, each containing the same number of observations as the original sample of actual U.S. data, then re-estimates the model 1,000 times using these artificial data sets. The standard errors shown in Table 1 correspond to the standard deviations of the individual parameter estimates taken across these 1,000 replications.

To assist in interpreting many of the results presented below, the table reports three sets of estimates: the first obtained from an unconstrained version of the model with an "endogenous inflation target" in which all 14 parameters are estimated freely, the second obtained from a constrained version of the model with an "exogenous inflation target" in which $\delta_{e}$ and $\delta_{z}$ remain fixed at zero while the remaining 12 parameters are estimated freely, and the third obtained from another constrained version of the model with "backwardlooking price setting" in which $\alpha$ remains fixed at one while the remaining 13 parameters are estimated freely. For all three versions of the model, the estimates imply a degree of 
backward-looking behavior of consumption, as measured by a habit-formation parameter $\gamma$ around 0.25 , that is significant both economically and statistically. For all three versions of the model, the estimates reveal that both inflation and output growth enter significantly into the Taylor rule for the nominal interest rate; the policy response to inflation, however, appears considerably more vigorous than the associated response to output growth. And for all three versions of the model, the estimates suggest that the preference shock is highly persistent while the cost-push and monetary policy shocks are much less so. The estimates of the volatility parameters $\sigma_{a}, \sigma_{e}, \sigma_{z}$, and $\sigma_{v}$ for the innovations also remain of roughly the same order of magnitude looking across the three specifications.

For the unconstrained, "endogenous target" model, the estimates $\sigma_{\pi}=0.0000, \delta_{e}=$ 0.0010 , and $\delta_{z}=0.0002$ attribute all movements in the inflation target to the Federal Reserve's deliberate response to the two supply shocks: the exogenous shock to the inflation target plays no role in explaining the data. A clear interpretation of these parameter estimates emerges from Figure 2, which plots impulse responses generated from this version of the model. In particular, the figure shows that under the estimated policy rule, the inflation target falls by 41 basis points following a favorable one-standard-deviation cost-push shock; the model's linearity then implies that, symmetrically, the inflation target rises by the same amount following a similarly-sized adverse cost-push disturbance. The figure also reveals that by adjusting the inflation target in this manner, the Federal Reserve's policy works to completely insulate output from the effects of those cost-push shocks: under the estimated policy, a favorable cost-push shock causes output to fall very slightly, by 4 basis points, before returning to its steady-state level. The smaller estimated value for $\delta_{z}$ implies a correspondingly smaller 6.4-basis-point adjustment of the inflation target following a one-standard-deviation technology shock.

Comparing the point estimates of $\delta_{e}$ and $\delta_{z}$ with their standard errors suggests that the policy response to the cost-push shock is more important, not just economically, as shown in Figure 2, but statistically as well. However, Table 1 also reports the maximized 
value $L^{*}$ of the log-likelihood function for each version of the model. Since the "exogenous target" model is a constrained version of the endogenous target model, the likelihood ratio statistic of 1.62 , formed by doubling the difference between $L^{*}$ for the two models, suggests that, in fact, the null hypothesis that $\delta_{e}=0$ and $\delta_{z}=0$ cannot be rejected with any reasonable degree of confidence. Thus, while the estimates of the best-fitting, endogenous target model do provide some support for a combined version of the stories told by Blinder (1982), Hetzel (1998), Mayer (1998), Bomfim and Rudebusch (2000), and Orphanides and Wilcox (2002), according to which the Federal Reserve acted consistently over the postwar period to translate the purely transitory price pressures brought about by supply shocksparticularly cost-push shocks - into more persistent movements in inflation, considerable uncertainty remains about the true source of movements in the Federal Reserve's inflation target, so that one cannot statistically reject the exogenous target model that depicts those movements as purely random.

On the other hand, for both the endogenous and exogenous target models, the estimate of the Phillips curve parameter $\alpha$ measuring the degree of backward-looking behavior in price setting lies up against its lower bound of zero and has a small standard error. What's more, the maximized value of the log-likelihood function falls considerably when the constrained $\alpha=1$ is imposed in estimating the model with backward-looking price setting: a likelihood ratio test firmly rejects the null hypothesis that this constraint is true. Why is backward-looking behavior in price setting found to be unimportant here, contrasting with the earlier results of Fuhrer and Moore $(1995 a, 1995 b)$ and many others? Two features of the model estimated here that are often absent from those that suggest a more prominent role for backward-looking price setting help account for this finding. First, Rotemberg (1997) argues that the inflation persistence explained by the backward-looking terms in Fuhrer and Moore's Phillips curve can also be accounted for in a purely forward-looking model with serially correlated behavioral disturbances and here, indeed, both the preference and technology shocks follow highly persistent autoregressive processes. Second and perhaps more impor- 
tant, Kozicki and Tinsley (2003) suggest that shifts in the central bank's inflation target can also substitute for backward-looking terms in the Phillips curve in explaining inflation persistence. In fact, Cogley and Sbordone (2005) obtain this same result: an estimated coefficient of zero on the backward-looking term in a New Keynesian Phillips curve that also allows for drift in the Federal Reserve's inflation target. Hence, the results from Table 1 indicate that here, the introduction of a backward-looking term in the Phillips curve not only turns out to be unnecessary for explaining the postwar U.S. data, but actually leads to a significant deterioration in the model's statistical fit.

The basic workings of the better-fitting and statistically indistinguishable endogenous and exogenous target models are most conveniently illustrated by tracing out the impulse responses generated by the exogenous target variant, since in that case, the effects of the cost-push and technology shocks are not distorted by the coincident changes in the inflation target. Hence, Figure 3 displays these impulse responses. The graphs confirm that the preference shock acts as an exogenous demand-side disturbance, moving output, inflation, and the short-term nominal interest rate in the same direction. The cost-push and technology shocks, by contrast, act as supply-side disturbances, moving output and inflation in opposite directions. As noted above, the random walk specification for technology serves to distinguish between the effects of these two supply-side shocks: a favorable cost-push shock leads to a purely transitory increase in output, whereas a favorable technology shock permanently raises the level of output. In addition, the larger and more persistent increase in output growth that follows the technology shock implies that under the estimated Taylor rule, the nominal interest rate rises after the technology shock but falls after the cost-push shock.

A one-standard-deviation innovation to the transitory monetary policy shock works to increase the annualized short-term nominal interest rate by about 36 basis points and keeps the interest rate above its steady-state level for two years. This exogenous monetary tightening generates a decline in output of about 30 basis points and a fall in inflation of about 50 basis points; these movements in output and inflation, like that of the interest rate itself, 
persist over a period of two years. Meanwhile, a one-standard-deviation shock to the inflation target leads to a permanent 40-basis-point increase in both the inflation and nominal interest rates. As inflation overshoots in the short run, while the nominal interest rate adjusts only gradually, the real interest rate falls, generating an 11-basis point rise in output that persists for more than two years.

The last column of Figure 3 shows the how the welfare-theoretic measure of the output gap, defined in Appendix B as the percentage deviation of output in equilibrium from its efficient or Pareto optimal level, responds to each of the model's five shocks. The cost-push, monetary policy, and inflation target shocks do not influence the efficient level of output in this model; hence, the output gap moves in lockstep with output itself after each of these shocks. On the other hand, the preference and technology shocks do impact on the efficient level of output, generating impulse responses in the output gap that differ from those in output. Most notably, the efficient level of output rises more strongly than equilibrium output, so that the output gap declines even as output rises, after a positive technology shock. Gali (2003) emphasizes this result: that the behavior of output and the output gap can differ quite markedly in New Keynesian models such as the one used here.

Tables 2 and 3 present forecast error variance decompositions performed with the endogenous and exogenous target models. According to both model variants, technology shocks represent the dominant source of movements in output, although preference and monetary policy shocks do play a supporting role in driving short-run output fluctuations. Preference shocks become more important in accounting for movements in the nominal interest rate. And both model variants attribute low-frequency movements in inflation to changes in the inflation target, although the unconstrained model interprets these movements as reflecting the Federal Reserve's deliberate policy response to cost-push shocks, whereas the constrained model views them instead as purely exogenous.

Figures 4 and 5 superimpose estimates of the Federal Reserve's inflation target on the graph of actual U.S. inflation shown originally as Figure 1. These estimates reflect informa- 
tion contained in the full sample, that is, they are generated using the smoothing algorithms described by Hamilton (1994, pp.394-397) and generalized by Kohn and Ansley (1983) to handle cases like the one that arises here, where the state covariance matrix turns out to be singular. Consistent with all of the previous results, the two model variants have very similar implications for the evolving path of the inflation target, although the sources of the inferred movements differ: those in Figure 4 are interpreted as reflections of the Federal Reserve's deliberate response to supply-side disturbances - mainly cost-push shocks - while those in Figure 5 are taken as purely exogenous. For the endogenous target model, Figure 4 shows that the estimated inflation target rises from 1.24 percent in 1959:1 to twin peaks of 8.52 percent in 1974:4 and 8.12 percent in 1980:4. The estimated target hits its post-1980 low of 1.80 percent in both 1998:2 and 2002:1 before rising to 2.48 percent in 2004:2. Meanwhile, for the exogenous target model, Figure 5 indicates that the estimated target starts at 1.18 percent in 1959:1, peaks at 7.98 percent in $1974: 4$ and 8.02 percent in 1980:4, falls to its post-1980 low of 1.70 percent in both 1998:2 and 2002:1, and stands at 2.14 percent in 2004:2. The estimates of the Federal Reserve's inflation target shown here in Figures 4 and 5 appear slightly more volatile and hit higher peaks than those obtained and displayed by Kozicki and Tinsley (2001, Figure 6, p.643) and Cogley and Sbordone (2005, Figure 2, p.14), but bear a closer resemblance to those derived by Kozicki and Tinsley (2003, Figure 2, p.19), which have the target rising to about 7 percent in the mid-1970s and remaining high until the early 1980s.

As noted above, the structural model developed and estimated here responds positively to the Lucas (1976) critique by cleanly separating out the parameters describing the central bank's policy rule - parameters that will change when the conduct of monetary policy changes - from those describing private tastes and technologies - which ought to remain invariant to shifts in the policy rule. Hence, the estimated model provides a detailed answer to questions such as: how would the U.S. economy have behaved if, instead of allowing inflation to rise and fall, the Federal Reserve had maintained a constant inflation target throughout 
the postwar period? Along those lines, Figures 6 and 7 compare the actual paths for inflation, the short-term nominal interest rate, and output growth as observed in the historical data to those that, according to the endogenous and exogenous target versions of the model, would have been realized under a constant inflation target, that is, in the counterfactual case where instead of equalling their estimated values, the parameters $\sigma_{\pi}, \delta_{e}$, and $\delta_{z}$ all equal zero. Each figure also compares the model's implications for the evolution of the output gap under the historical (estimated) and counterfactual policy rules.

Of course, inflation becomes much more stable under the counterfactual scenario. In particular, estimates from the endogenous target model indicate that without changes in the inflation target, U.S. inflation would have peaked at only 3.92 percent in 1975:1, while estimates from the exogenous target model imply that inflation would have hit a postwar high of 4.56 percent, also in 1975:1. Through the Fisher effect, the nominal interest rate follows the inflation rate by becoming lower and more stable under the counterfactual scenario. However, the two stationary measures of real economic activity, output growth and the output gap, look much the same under the counterfactual scenario as they do historically. This last finding echoes those shown previously in Tables 2 and 3, which attribute virtually all of the observed movements in output to a combination of preference, technology, and monetary policy shocks in the short run and to technology shocks in the long run, but also raises the question of how sensitive the results are to changes in the parameter $\alpha$, measuring the degree of backward-looking behavior in price setting.

Hence, Figures 8-10 display impulse responses, smoothed estimates of the Federal Reserve's inflation target, and the results of the counterfactual simulation derived using the constrained model with backward-looking price setting described previously in Table 1. As noted above, this model variant sets $\alpha=1$, so that the Phillips curve specification contains forward- and backward-looking elements of roughly equal importance, similar to those used by Fuhrer and Moore $(1995 a, 1995 b)$. Naturally, some of the implications of this constrained, "backward-looking" model differ from those of the two better-fitting endogenous and exoge- 
nous target model variants for which the estimated value of $\alpha$ equals zero. The impulse responses shown in Figure 8, for example, reveal that for the backward-looking model, an exogenous shock that increases the inflation target by 24 basis points causes output to rise by 14 basis points on impact. Since, Figure 3 indicates that in the exogenous target model a shock that increases the inflation target by 40 basis points causes output to rise by 11 basis points on impact, the output effects of changes in the inflation become more than twice as large with $\alpha=1$ as they are with $\alpha=0$.

Figure 9 plots a series for the estimated inflation target derived using the backwardlooking model that is smoother than those shown in Figures 4 and 5 . The inflation target in Figure 9 also peaks at lower rates - 7.14 percent in both 1974:4 and 1980:4 - than those in Figures 4 and 5. According to Figure 10, therefore, even in the counterfactual scenario with a constant inflation target, U.S. inflation would have risen above 5 percent, to a peak of 5.72 percent in 1974:4. But while, as shown in Figure 8, the output effects of any given shift in the inflation target are larger in the backward-looking model, the estimated movements in the inflation target shown in Figure 9 are smaller. Hence, using a much different Phillips curve specification, Figure 10 actually confirms the robustness of the general conclusion suggested earlier by Figures 6 and 7: that by maintaining a constant inflation target throughout the postwar period, the Federal Reserve could have lowered both the level and volatility of inflation without adding much instability to the real economy.

\section{Conclusions, Interpretations, Directions for Future Work}

The estimates of the Federal Reserve's inflation target shown in Figures 4 and 5, together with the counterfactual histories traced out in Figures 6 and 7, bring the analysis full circle, back to Friedman's (1968) "always and everywhere" quote shown at the outset. These figures, derived from an estimated New Keynesian model, suggest that the Federal Reserve's 
inflation target rose from about $11 / 4$ percent in 1959 to hit twin peaks at or above 8 percent in 1974 and 1980 before falling back below $21 / 2$ percent by the end of the sample period in 2004. These figures also suggest that absent those target changes, U.S. inflation would never have exceeded 4 or $41 / 2$ percent. Thus, by attributing the bulk of inflation's rise and fall to Federal Reserve policy, the results confirm that to a large extent indeed, postwar U.S. inflation is a "monetary phenomenon."

What's more, estimates from the best-fitting, endogenous target version of the model provide some support for stories told previously by Blinder (1982), Hetzel (1998), and Mayer (1998), which attribute the rise in U.S. inflation during the 1960s and 1970s to a systematic tendency for Federal Reserve policy to translate short-run price pressures set off by adverse supply-side shocks - particularly cost-push shocks - into more persistent movements in the inflation rate itself. And, symmetrically, those same estimates confirm Bomfim and Rudebusch (2000) and Orphanides and Wilcox's (2002) suggestion that, since 1980, the Federal Reserve has acted "opportunistically" to bring inflation back down in the aftermath of more favorable supply-side disturbances. But while the results bring together these two sets of stories to provide a unified explanation of inflation's long-run rise and fall, they also indicate that considerable uncertainty remains about the true source of movements in the Federal Reserve's inflation target: the best-fitting version of the model, which interprets those movements as part of a deliberate policy response to exogenous supply-side shocks hitting the economy, turns out to be statistically indistinguishable from the alternative, exogenous target variant that depicts movements in the inflation target as purely random.

Stepping back from these literal interpretations of the two model variants and looking more broadly at the results, some links to other recent contributions to the literature on postwar U.S. monetary history begin to appear. The results from the endogenous target model, for instance, also provide some support for Ireland (1999) and Chappell and McGregor's (2004) interpretation of the data, according to which Kydland and Prescott (1977) and Barro and Gordon's (1983) time-consistency problem accounts for the Federal Reserve's 
unwillingness to prevent inflation from rising in the face of adverse supply-side shocks as well as its ability to bring inflation back down following more favorable supply-side disturbances. Alternatively, to the extent that the adverse supply shocks that hit the U.S. economy during the 1970s can be blamed for inaccuracies in official estimates of the output gap, the results obtained here can be squared with Orphanides' (2002) account of how mismeasurement of the output gap led Federal Reserve officials to mistakenly adopt an overly accommodative monetary policy throughout that decade, fueling the coincident rise in inflation. Finally, the results from the exogenous target model might be reinterpreted in line with Sargent's (1999) hypothesis that Federal Reserve officials actively pushed inflation higher during the 1960s and 1970s in a futile effort to exploit a misperceived Phillips curve trade-off. Clearly, further extensions to and refinements of the empirical New Keynesian model developed here are called for, in an effort to discriminate more sharply between these competing views of the data, to understand more fully the policy mistakes of the past, and to guard more reliably against similar mistakes in the future.

\section{Appendix A: Equilibrium Conditions}

This Appendix derives the model's equilibrium conditions, which take the form of (13)-(24) after they are log-linearized.

The representative household chooses $C_{t}, h_{t}, B_{t}$, and $M_{t}$ for all $t=0,1,2, \ldots$ to maximize its expected utility subject to the budget constraint (1) for all $t=0,1,2, \ldots$ The first-order conditions for this problem can be written as

$$
\begin{gathered}
\Lambda_{t}=\frac{a_{t}}{C_{t}-\gamma C_{t-1}}-\beta \gamma E_{t}\left(\frac{a_{t+1}}{C_{t+1}-\gamma C_{t}}\right), \\
a_{t}=\Lambda_{t}\left(W_{t} / P_{t}\right), \\
\Lambda_{t}=\beta R_{t} E_{t}\left(\Lambda_{t+1} / \Pi_{t+1}\right),
\end{gathered}
$$




$$
M_{t} / P_{t}=\left(a_{t} / \Lambda_{t}\right)\left[R_{t} /\left(R_{t}-1\right)\right],
$$

and (1) with equality for all $t=0,1,2, \ldots$, where $\Lambda_{t}$ denotes the nonnegative Lagrange multiplier on the budget constraint expressed in real terms for period $t$. Equation (25) identifies the multiplier $\Lambda_{t}$ with the marginal utility of consumption during period $t$, adjusted to account for the habit-persistence effects that carry over into $t+1$. Since utility is linear in hours worked, (26) equates the marginal rate of substitution between consumption and leisure to the real wage. The Euler equation (27) relates the intertemporal marginal rate of substitution to the real interest rate, while (28) takes the form of a money demand relationship, implying that real balances rise as consumption rises and the nominal interest rate falls.

The representative intermediate-goods-producing firm chooses $P_{t}(i)$ for all $t=0,1,2, \ldots$ to maximize its real market value, given by

$$
E_{0} \sum_{t=0}^{\infty} \beta^{t} \Lambda_{t}\left[D_{t}(i) / P_{t}\right]
$$

where $\beta^{t} \Lambda_{t}$ measures the marginal utility value to the representative household of an additional unit of real profits received in the form of dividends during period $t$ and where

$$
\frac{D_{t}(i)}{P_{t}}=\left[\frac{P_{t}(i)}{P_{t}}\right]^{1-\theta_{t}} Y_{t}-\left[\frac{P_{t}(i)}{P_{t}}\right]^{-\theta_{t}}\left(\frac{W_{t}}{P_{t}}\right)\left(\frac{Y_{t}}{Z_{t}}\right)-\frac{\phi}{2}\left[\frac{P_{t}(i)}{\Pi_{t-1}^{\alpha}\left(\Pi_{t}^{*}\right)^{1-\alpha} P_{t-1}(i)}-1\right]^{2} Y_{t}
$$

measures the firm's real profits during period $t$ in light of the requirement that it sell its output on demand at price $P_{t}(i)$. The first-order conditions for this problem are

$$
\begin{aligned}
0= & \left(1-\theta_{t}\right)\left[\frac{P_{t}(i)}{P_{t}}\right]^{-\theta_{t}}+\theta_{t}\left[\frac{P_{t}(i)}{P_{t}}\right]^{-\theta_{t}-1}\left(\frac{W_{t}}{P_{t}}\right)\left(\frac{1}{Z_{t}}\right) \\
& -\phi\left[\frac{P_{t}(i)}{\Pi_{t-1}^{\alpha}\left(\Pi_{t}^{*}\right)^{1-\alpha} P_{t-1}(i)}-1\right]\left[\frac{P_{t}}{\Pi_{t-1}^{\alpha}\left(\Pi_{t}^{*}\right)^{1-\alpha} P_{t-1}(i)}\right] \\
& +\beta \phi E_{t}\left\{\left(\frac{\Lambda_{t+1}}{\Lambda_{t}}\right)\left[\frac{P_{t+1}(i)}{\Pi_{t}^{\alpha}\left(\Pi_{t+1}^{*}\right)^{1-\alpha} P_{t}(i)}-1\right]\left[\frac{P_{t+1}(i)}{\Pi_{t}^{\alpha}\left(\Pi_{t+1}^{*}\right)^{1-\alpha} P_{t}(i)}\right]\left[\frac{P_{t}}{P_{t}(i)}\right]\left(\frac{Y_{t+1}}{Y_{t}}\right)\right\}
\end{aligned}
$$


and (5) with equality for all $t=0,1,2, \ldots$. In the absence of price adjustment costs, when $\phi=0,(30)$ simply implies that the firm sets its price $P_{t}(i)$ as a markup $\theta_{t} /\left(\theta_{t}-1\right)$ over marginal cost $W_{t} / Z_{t}$. Hence, as suggested above, $\theta_{t} /\left(\theta_{t}-1\right)$ can be interpreted as the firm's desired markup, and random fluctuations in $\theta_{t}$ act as shocks to the firm's desired markup. Costly price adjustment $(\phi>0)$ then implies that actual markups deviate from, but tend to gravitate towards, their desired level as firms respond optimally to the shocks that hit the economy.

After imposing the symmetry conditions $Y_{t}(i)=Y_{t}, h_{t}(i)=h_{t}, D_{t}(i)=D_{t}$, and $P_{t}(i)=P_{t}$ for all $i \in[0,1]$ and $t=0,1,2, \ldots$ and the market-clearing conditions $M_{t}=M_{t-1}+T_{t}$ and $B_{t}=B_{t-1}=0$ for all $t=0,1,2, \ldots$, and using (5), (26), (28), and (29) to solve for $h_{t}, W_{t}, M_{t}$, and $D_{t}$, the household's budget constraint (1) can be rewritten as the economy's aggregate resource constraint

$$
Y_{t}=C_{t}+\frac{\phi}{2}\left[\frac{\Pi_{t}}{\Pi_{t-1}^{\alpha}\left(\Pi_{t}^{*}\right)^{1-\alpha}}-1\right]^{2} Y_{t}
$$

and the intermediate-goods-producing firm's optimal price adjustment rule (30) simplifies to

$$
\begin{aligned}
\theta_{t}-1= & \theta_{t}\left(\frac{a_{t}}{\Lambda_{t} Z_{t}}\right)-\phi\left[\frac{\Pi_{t}}{\Pi_{t-1}^{\alpha}\left(\Pi_{t}^{*}\right)^{1-\alpha}}-1\right]\left[\frac{\Pi_{t}}{\Pi_{t-1}^{\alpha}\left(\Pi_{t}^{*}\right)^{1-\alpha}}\right] \\
& +\beta \phi E_{t}\left\{\left(\frac{\Lambda_{t+1}}{\Lambda_{t}}\right)\left[\frac{\Pi_{t+1}}{\Pi_{t}^{\alpha}\left(\Pi_{t+1}^{*}\right)^{1-\alpha}}-1\right]\left[\frac{\Pi_{t+1}}{\Pi_{t}^{\alpha}\left(\Pi_{t+1}^{*}\right)^{1-\alpha}}\right]\left(\frac{Y_{t+1}}{Y_{t}}\right)\right\}
\end{aligned}
$$

for all $t=0,1,2, \ldots$. Equations (31) and (32), together with (2), (4), (6)-(12), (25), and (27), form a system of equilibrium conditions that completely determines the behavior of the thirteen variables $Y_{t}, C_{t}, \Pi_{t}, R_{t}, g_{t}^{y}, g_{t}^{\pi}, r_{t}^{r \pi}, \Lambda_{t}, a_{t}, \theta_{t}, Z_{t}, v_{t}$, and $\Pi_{t}^{*}$. When rewritten in terms of the model's stationary variables and log-linearized, this system takes the form of $(13)-(24)$ 


\section{Appendix B: The Efficient Level of Output and the Output Gap}

This appendix derives conditions that define the economy's efficient, or Pareto optimal, level of output and a corresponding welfare-theoretic notion of the output gap.

Consider a social planner who can circumvent the frictions that make markets for the intermediate goods monopolistically competitive in equilibrium, that give rise to the explicit costs of nominal price adjustment, and that imply that real money balances appear in representative household's utility function. This social planner chooses an amount $Q_{t}$ of the finished good to allocate to the household's consumption and an amount $n_{t}(i)$ of the household's time to allocate to production of each intermediate good $i \in[0,1]$ for all $t=0,1,2, \ldots$ in order to maximize the household's expected utility, now measured by

$$
E_{0} \sum_{t=0}^{\infty} \beta^{t} a_{t}\left[\ln \left(Q_{t}-\gamma Q_{t-1}\right)-\int_{0}^{1} n_{t}(i) d i\right]
$$

subject only to the aggregate feasibility constraint

$$
Z_{t}\left[\int_{0}^{1} n_{t}(i)^{\left(\theta_{t}-1\right) / \theta_{t}} d i\right]^{\theta_{t} /\left(\theta_{t}-1\right)} \geq Q_{t}
$$

for all $t=0,1,2, \ldots$, reflecting the use of the same constant-returns-to-scale technologies

described by (3) and (5). The first-order conditions for this social planner's problem can be written as

$$
\begin{gathered}
\Xi_{t}=\frac{a_{t}}{Q_{t}-\gamma Q_{t-1}}-\beta \gamma E_{t}\left(\frac{a_{t+1}}{Q_{t+1}-\gamma Q_{t}}\right) \\
a_{t}=\Xi_{t} Z_{t}\left(Q_{t} / Z_{t}\right)^{1 / \theta_{t}} n_{t}(i)^{-1 / \theta_{t}}
\end{gathered}
$$

for all $i \in[0,1]$, and (33) with equality for all $t=0,1,2, \ldots$, where $\Xi_{t}$ denotes the nonnegative Lagrange multiplier on (33) for period $t$.

Equation (35) implies that it is optimal for the social planner to choose $n_{t}(i)=n_{t}$ for all 
$i \in[0,1]$ and $t=0,1,2, \ldots$, where

$$
n_{t}=\left(\Xi_{t} / a_{t}\right)^{\theta_{t}} Z_{t}^{\theta_{t}}\left(Q_{t} / Z_{t}\right)
$$

Substituting this last relationship into (33) yields

$$
\Xi_{t}=a_{t} / Z_{t}
$$

Hence, (34) implies that the efficient level of output $Q_{t}$ must satisfy

$$
\frac{1}{Z_{t}}=\frac{1}{Q_{t}-\gamma Q_{t-1}}-\beta \gamma E_{t}\left[\left(\frac{a_{t+1}}{a_{t}}\right)\left(\frac{1}{Q_{t+1}-\gamma Q_{t}}\right)\right]
$$

for all $t=0,1,2, \ldots$. Equation (36) implies that, like the equilibrium level of output $Y_{t}$, the efficient level of output $Q_{t}$ inherits a unit root from the process (6) for technology. However, the transformed variable $q_{t}=Q_{t} / Z_{t}$ remains stationary, as does the output gap

$$
x_{t}=Q_{t} / Y_{t}
$$

defined as the ratio of the efficient and equilibrium levels of output. Log-linearized versions of (36) and (37) can be added to the system consisting of (13)-(24) to determine how this welfare-theoretic output gap responds to the model's exogenous shocks.

\section{References}

Barro, Robert J. and David B. Gordon. "A Positive Theory of Monetary Policy in a Natural Rate Model." Journal of Political Economy 91 (August 1983): 589-610.

Blanchard, Olivier Jean and Charles M. Kahn. "The Solution of Linear Difference Models Under Rational Expectations." Econometrica 48 (July 1980): 1305-1311. 
Blinder, Alan S. "The Anatomy of Double-Digit Inflation in the 1970s." In Robert E. Hall, ed. Inflation: Causes and Effects. Chicago: University of Chicago Press, 1982.

Bomfim, Antulio N. and Glenn D. Rudebusch. "Opportunistic and Deliberate Disinflation Under Imperfect Credibility." Journal of Money, Credit, and Banking 32 (November 2000, Part 1): 707-721.

Calvo, Guillermo A. "Staggered Prices in a Utility-Maximizing Framework." Journal of Monetary Economics 12 (September 1983): 383-398.

Chappell, Henry W., Jr. and Rob Roy McGregor. "Did Time Inconsistency Contribute to the Great Inflation? Evidence from the FOMC Transcripts." Economics and Politics 16 (November 2004): 233-251.

Cho, Seonghoon and Antonio Moreno. "A Small-Sample Study of the New Keynesian Macro Model." Journal of Money, Credit, and Banking 38 (September 2006): 1461-1481.

Clarida, Richard, Jordi Gali, and Mark Gertler. "The Science of Monetary Policy: A New Keynesian Perspective.” Journal of Economic Literature 37 (December 1999): 16611707.

Cogley, Timothy and Argia M. Sbordone. "A Search for a Structural Phillips Curve." Staff Report 203. New York: Federal Reserve Bank of New York, March 2005.

Dewachter, Hans and Marco Lyrio. "Macro Factors and the Term Structure of Interest Rates." Journal of Money, Credit, and Banking 38 (February 2006): 119-140.

Driscoll, John C. "On the Microfoundations of Aggregate Demand and Aggregate Supply." Manuscript. Providence: Brown University, October 2000.

Efron, Bradley and Robert J. Tibshirani. An Introduction to the Bootstrap. Boca Raton: Chapman and Hall/CRC Press, 1993. 
Erceg, Christopher J. and Andrew T. Levin. "Imperfect Credibility and Inflation Persistence." Journal of Monetary Economics 50 (May 2003): 915-944.

Friedman, Milton. "Inflation: Causes and Consequences." In Dollars and Deficits: Living With America's Economic Problems. Englewood Cliffs: Prentice-Hall, 1968.

Fuhrer, Jeffrey C. "Habit Formation in Consumption and Its Implications for MonetaryPolicy Models." American Economic Review 90 (June 2000): 367-390.

Fuhrer, Jeffrey C. and George R. Moore. "Inflation Persistence." Quarterly Journal of Economics 110 (February 1995a): 127-159.

Fuhrer, Jeffrey C. and George R. Moore. "Monetary Policy Trade-offs and the Correlation between Nominal Interest Rates and Real Output." American Economic Review 85 (March 1995b): 219-239.

Gali, Jordi. "New Perspectives on Monetary Policy, Inflation, and the Business Cycle." In Mathias Dewatripont, Lars Peter Hansen, and Stephen J. Turnovsky, eds. Advances in Economics and Econometrics: Theory and Applications, Eighth World Congress, Volume III. Cambridge: Cambridge University Press, 2003.

Gali, Jordi and Mark Gertler. "Inflation Dynamics: A Structural Econometric Analysis." Journal of Monetary Economics 44 (October 1999): 195-222.

Gavin, William T., Benjamin D. Keen, and Michael R. Pakko. "The Monetary Instrument Matters." Federal Reserve Bank of St. Louis Review 87 (September/October 2005): 633-658.

Gurkaynak, Refet S., Brian Sack, and Eric Swanson. "The Sensitivity of Long-Term Interest Rates to Economic News: Evidence and Implications for Macroeconomic Models." American Economic Review 95 (March 2005): 425-436.

Hamilton, James D. Time Series Analysis. Princeton: Princeton University Press, 1994. 
Hetzel, Robert L. "Arthur Burns and Inflation." Federal Reserve Bank of Richmond Economic Quarterly 84 (Winter 1998): 21-44.

Ireland, Peter N. "Does the Time-Consistency Problem Explain the Behavior of Inflation in the United States?" Journal of Monetary Economics 44 (October 1999): 279-291.

Ireland, Peter N. "Technology Shocks in the New Keynesian Model." Review of Economics and Statistics 86 (November 2004a): 923-936.

Ireland, Peter N. "Money's Role in the Monetary Business Cycle." Journal of Money, Credit, and Banking 36 (December 2004b): 969-983.

King, Robert G., Charles I. Plosser, and Sergio T. Rebelo. "Production, Growth, and Business Cycles: I. The Basic Neoclassical Model." Journal of Monetary Economics 21 (March/May 1988): 195-232.

Klein, Paul. "Using the Generalized Schur Form to Solve a Multivariate Linear Rational Expectations Model." Journal of Economic Dynamics and Control 24 (September 2000): $1405-1423$.

Kohn, Robert and Craig F. Ansley. "Fixed Interval Estimation in State Space Models when Some of the Data are Missing or Aggregated." Biometrika 70 (December 1983): 683-688.

Kozicki, Sharon and Peter A. Tinsley. "Shifting Endpoints in the Term Structure of Interest Rates." Journal of Monetary Economics 47 (June 2001): 613-652.

Kozicki, Sharon and Peter A. Tinsley. "Alternative Sources of the Lag Dynamics of Inflation." In Price Adjustment and Monetary Policy: Proceedings of a Conference Held By the bank of Canada, November 2002. Ottawa: Bank of Canada, 2003.

Kozicki, Sharon and Peter A. Tinsley. "Permanent and Transitory Policy Shocks in an Empirical Macro Model with Asymmetric Information." Journal of Economic Dynamics 
and Control 29 (November 2005): 1985-2015.

Kydland, Finn E. and Edward C. Prescott. "Rules Rather than Discretion: The Inconsistency of Optimal Plans." Journal of Political Economy 85 (June 1977): 473-491.

Lucas, Robert E., Jr. "Econometric Policy Evaluation: A Critique." Carnegie-Rochester Conference Series on Public Policy 1 (1976): 19-46.

Malley, Jim, Apostolis Philippopoulos, and Ulrich Woitek. "Electoral Uncertainty, Fiscal Policy and Macroeconomic Fluctuations." Working Paper 1593. Munich: CESifo, November 2005.

Mayer, Thomas. Monetary Policy and the Great Inflation in the United States: The Federal Reserve and the Failure of Macroeconomic Policy, 1965-79. Cheltenham: Edward Elgar, 1998.

Orphanides, Athanasios. "Monetary Policy Rules and the Great Inflation." American Economic Review 92 (May 2002): 115-120.

Orphanides, Athanasios and David W. Wilcox. "The Opportunistic Approach to Disinflation." International Finance 5 (Spring 2002): 47-71.

Roberts, John M. "Monetary Policy and Inflation Dynamics." Finance and Economics Discussion Series 2004-62. Washington: Federal Reserve Board, October 2004.

Rotemberg, Julio J. "Sticky Prices in the United States." Journal of Political Economy 90 (December 1982): 1187-1211.

Rotemberg, Julio J. "Towards a Compact, Empirically-Verified Rational Expectations Model for Monetary Policy Analysis: A Comment." Carnegie-Rochester Conference Series on Public Policy 47 (December 1997): 231-241. 
Rudebusch, Glenn D. and Tao Wu. "A Macro-Finance Model of the Term Structure, Monetary Policy, and the Economy." Manuscript. San Francisco: Federal Reserve Bank of San Francisco, December 2004.

Salemi, Michael K. "Econometric Policy Evaluation and Inverse Control." Manuscript. Chapel Hill: University of North Carolina, July 2005.

Sargent, Thomas J. The Conquest of American Inflation. Princeton: Princeton University Press, 1999.

Smets, Frank and Raf Wouters. "Shocks and Frictions in US Business Cycles: A Bayesian DSGE Approach.” Manuscript. Frankfurt: European Central Bank, May 2003.

Steinsson, Jon. "Optimal Monetary Policy in an Economy with Inflation Persistence." Journal of Monetary Economics 50 (October 2003): 1425-1456.

Taylor, John B. "Discretion Versus Policy Rules in Practice." Carnegie-Rochester Conference Series on Public Policy 39 (December 1993): 195-214.

Woodford, Michael. Interest and Prices: Foundations of a Theory of Monetary Policy. Princeton: Princeton University Press, 2003. 
Table 1. Maximum Likelihood Estimates and Standard Errors

\begin{tabular}{|c|c|c|c|c|c|c|}
\hline & $\begin{array}{c}\text { Unconstrained } \\
\text { Model with } \\
\text { Endogenous Target }\end{array}$ & & $\begin{array}{c}\text { Constrained } \\
\text { Model with } \\
\text { Exogenous Target }\end{array}$ & & $\begin{array}{l}\text { Constrained } \\
\text { Model with } \\
\text { Backward-Looking } \\
\text { Price Setting }\end{array}$ & \\
\hline Parameter & Estimate & $\begin{array}{l}\text { Bootstrapped } \\
\text { Standard Error }\end{array}$ & Estimate & $\begin{array}{l}\text { Bootstrapped } \\
\text { Standard Error }\end{array}$ & Estimate & $\begin{array}{l}\text { Bootstrapped } \\
\text { Standard Error }\end{array}$ \\
\hline$\gamma$ & 0.2553 & 0.0776 & 0.2433 & 0.0705 & 0.2374 & 0.0709 \\
\hline$\alpha$ & 0.0000 & 0.0764 & 0.0000 & 0.0855 & 1.0000 & - \\
\hline$\rho_{\pi}$ & 0.9069 & 0.1435 & 0.8594 & 0.1623 & 0.5798 & 0.0690 \\
\hline$\rho_{g y}$ & 0.2347 & 0.0465 & 0.2617 & 0.0533 & 0.2527 & 0.0433 \\
\hline$\rho_{a}$ & 0.9105 & 0.0475 & 0.9097 & 0.0500 & 0.8935 & 0.0496 \\
\hline$\rho_{e}$ & 0.0060 & 0.2103 & 0.1310 & 0.2503 & 0.0000 & 0.0632 \\
\hline$\rho_{v}$ & 0.0546 & 0.0743 & 0.0711 & 0.0823 & 0.0132 & 0.0548 \\
\hline$\sigma_{a}$ & 0.0281 & 0.0091 & 0.0279 & 0.0092 & 0.0286 & 0.0070 \\
\hline$\sigma_{e}$ & 0.0007 & 0.0004 & 0.0015 & 0.0003 & 0.0038 & 0.0003 \\
\hline$\sigma_{z}$ & 0.0134 & 0.0017 & 0.0128 & 0.0023 & 0.0109 & 0.0016 \\
\hline$\sigma_{v}$ & 0.0027 & 0.0003 & 0.0028 & 0.0004 & 0.0024 & 0.0003 \\
\hline$\sigma_{\pi}$ & 0.0000 & 0.0004 & 0.0010 & 0.0002 & 0.0006 & 0.0003 \\
\hline$\delta_{e}$ & 0.0010 & 0.0004 & 0.0000 & - & 0.0004 & 0.0002 \\
\hline$\delta_{z}$ & 0.0002 & 0.0002 & 0.0000 & - & 0.0000 & 0.0001 \\
\hline & $L^{*}=2310.6812$ & & $L^{*}=2309.8728$ & & $L^{*}=2295.4659$ & \\
\hline
\end{tabular}

Notes: Where no standard error is reported, the parameter value has been constrained as indicated. $L^{*}$ denotes the maximized value of the log likelihood function. 
Table 2. Forecast Error Variance Decompositions, Unconstrained Model with Endogenous Inflation Target

\section{Output}

Quarters

Ahead

1

4

8

12

20

40

Prefer
13.
4.7
2.
1.3
0.7
0.4

Cost-Pus
0.2
0.1
0.0
0.0
0.0
0.0

Technology

74.5
91.2
96.1
97.6
98.7
99.4

Monetary

Inflation

Inflation

Quarters

Ahead

1

4

8

12

20

40

Preference
7.3
5.3
4.1
3.4
2.6
1.5

Cost-Push

47.5

51.4

61.5

68.1

76.1

84.7

Technology

28.0
28.1
22.9
19.1
14.6
9.7

$\begin{array}{cc}\text { Monetary } & \text { Inflation } \\ \text { Policy } & \text { Target }\end{array}$

Interest

Rate

Quarters

Ahead

Preference

Cost-Push

Monetary

Inflation

Policy

Target

$\begin{array}{cc}1 & 49.4 \\ 4 & 64.6 \\ 8 & 64.0 \\ 12 & 59.9 \\ 20 & 50.9 \\ 40 & 35.3\end{array}$

20.6
24.0
29.3
34.7
44.6
60.9

5.8

24.2

0.0

2.5

8.8

0.0

1.6

5.1

0.0

1.5

4.0

0.0

1.6

3.0

0.0

1.8

2.0

0.0

Note: Entries decompose the forecast error variance at each horizon into percentages due to each of the model's five shocks. 
Table 3. Forecast Error Variance Decompositions, Constrained Model with Exogenous Inflation Target

\section{Output}

Quarters

Ahead

Preference

Cost-Push Technology

$\begin{array}{cc}\text { Monetary } & \text { Inflation } \\ \text { Policy } & \text { Target }\end{array}$

1

13.5

3.9

1.5

66.7

87.7

94.6

96.7

98.1

0.4

0.2

99.1

14.3

1.6

5.1

0.6

2.3

0.1

2.2

0.2

1.3

0.1

0.8

0.1

0.4

0.4

0.0

\section{Inflation}

Quarters

Ahead

Preference

Cost-Push

Technology

Monetary Inflation

1

8.2

5.7

15.3

9.0

26.4

23.0

18.0

Policy

Target

8

4.4

6.9

3.7

5.7

4.2

14.8

10.9

22.2

27.8

18.6

43.7

14.5

56.2

11.9

63.8

8.8

73.2

2.6

6.6

5.4

83.7

\section{Interest}

Rate

Quarters

Ahead

Preference

Cost-Push

Technology

Monetary

Inflation

1

53.8

5.9

8.5

4.7

21.6

8.1

4.8

3.8

2.9

Target

8

66.8

1.4

2.9

2.2

53.9

0.8

1.7

2.0

10.3

17.4

24.1

30.2

0.6

1.2

40.7

58.1

Note: Entries decompose the forecast error variance at each horizon into percentages due to each of the model's five shocks. 


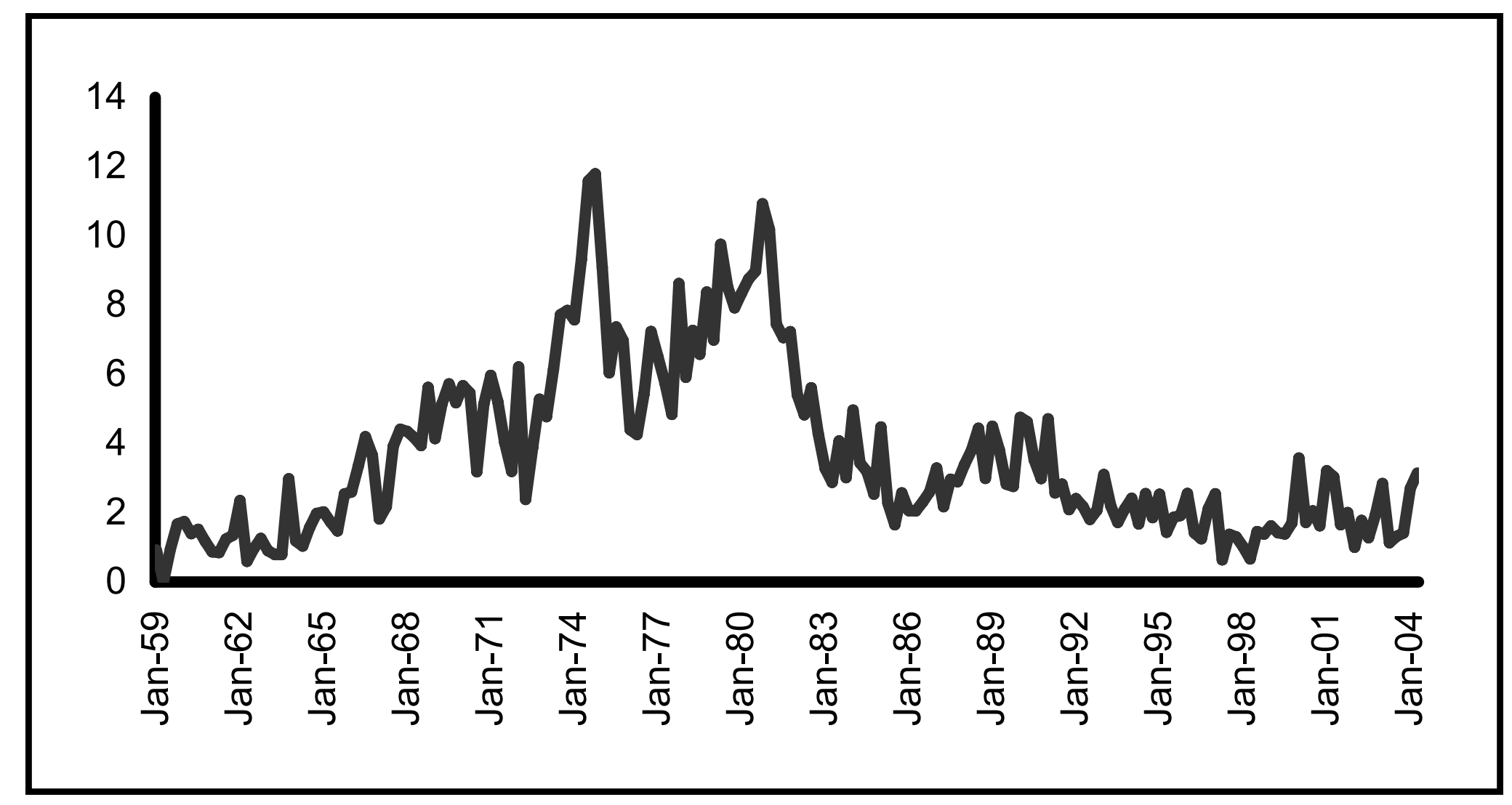

Figure 1. Inflation, United States. Measured by annualized, quarter-to-quarter percentage changes in the GDP implicit price deflator. 

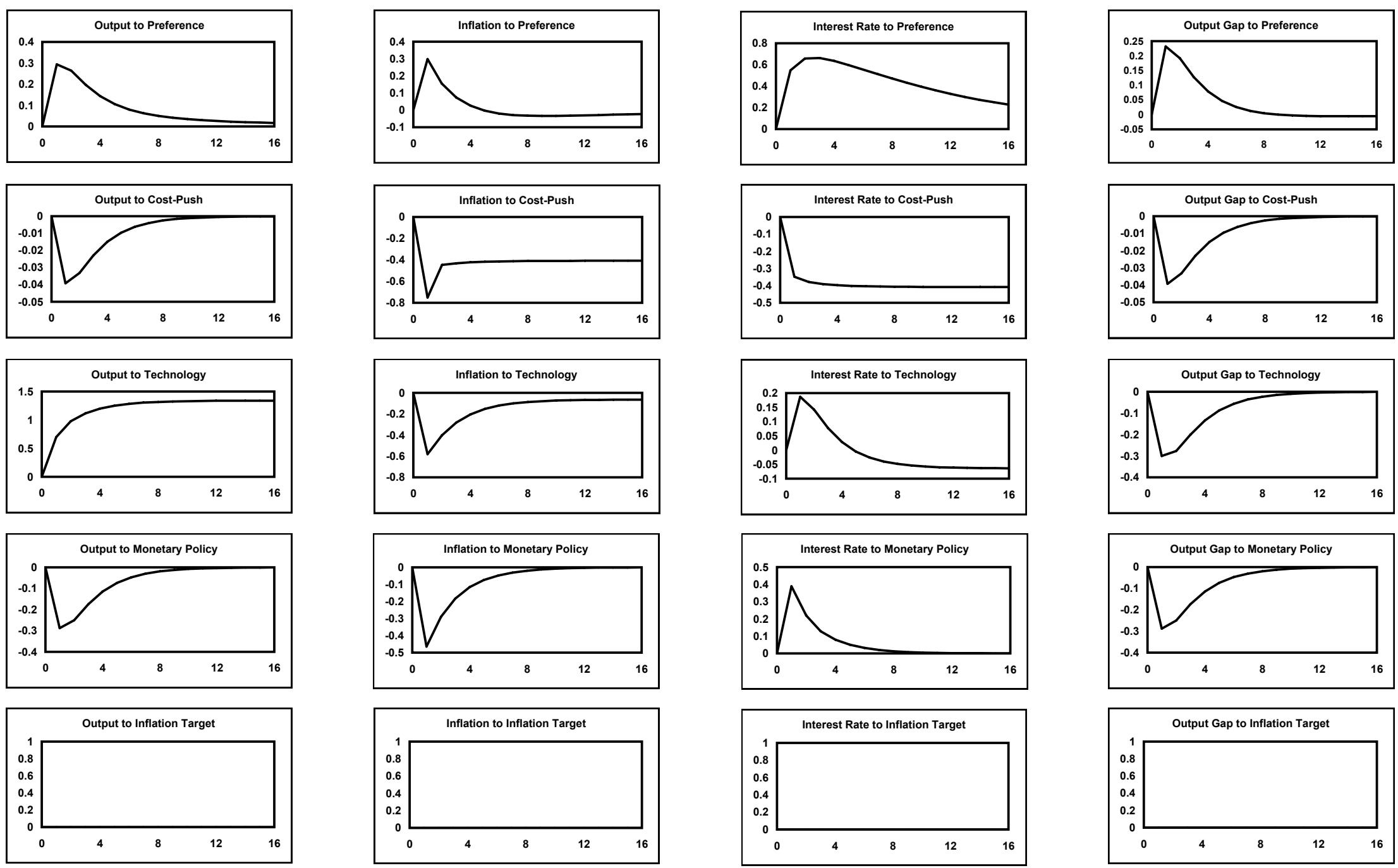

Figure 2. Impulse responses from the unconstrained model with an endogenous inflation target. Each panel shows the percentage-point response of one of the model's variables to a one-standard-deviation shock. The inflation and interest rates are expressed in annualized terms. 

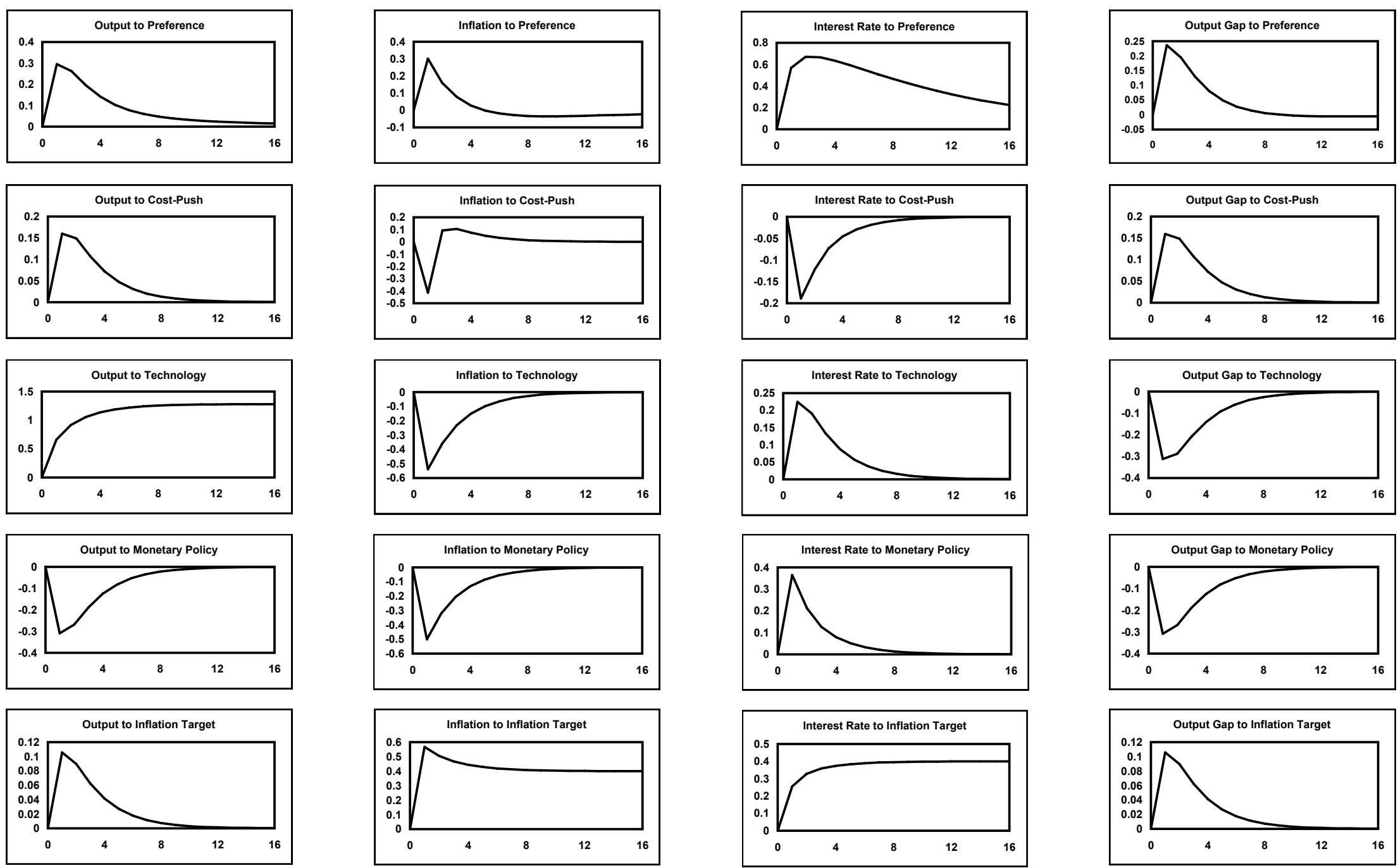

Figure 3. Impulse responses from the constrained model with an exogenous inflation target. Each panel shows the percentage-point response of one of the model's variables to a one-standard-deviation shock. The inflation and interest rates are expressed in annualized terms. 


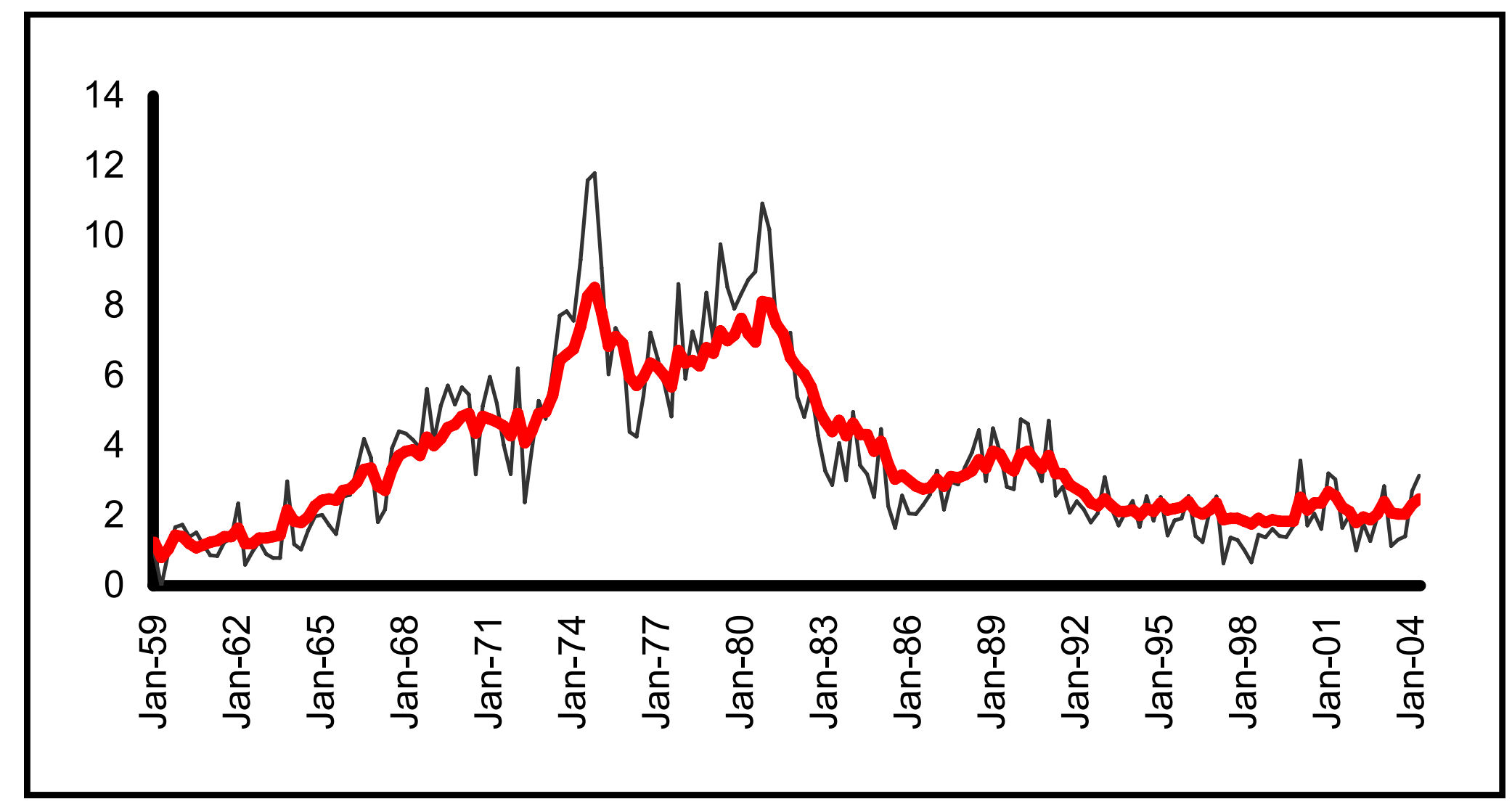

Figure 4. Actual inflation (thin black line) and the Federal Reserve's target (thick red line), as implied by the unconstrained model with an endogenous inflation target. 


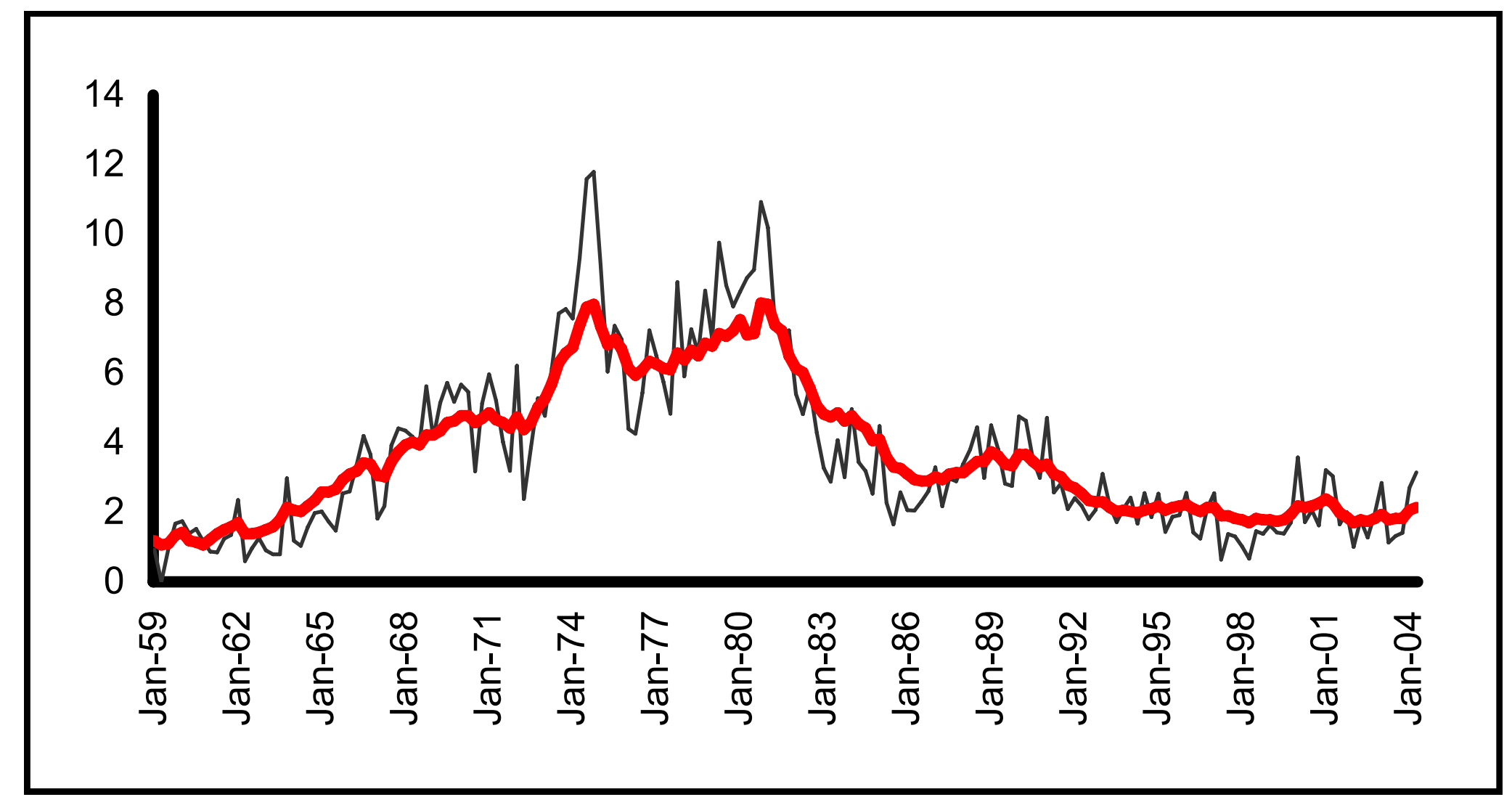

Figure 5. Actual inflation (thin black line) and the Federal Reserve's target (thick red line), as implied by the constrained model with an exogenous inflation target. 

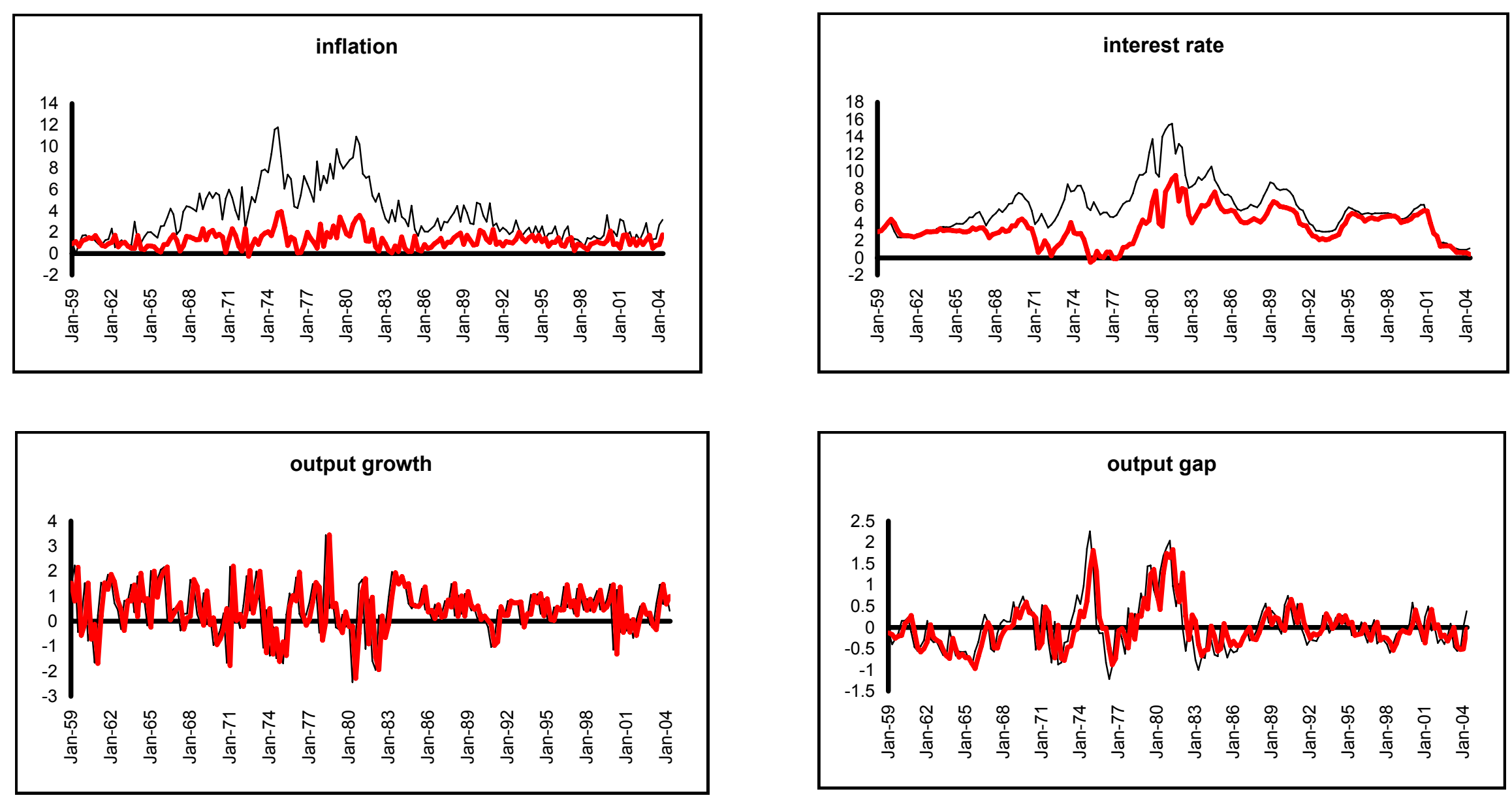

Figure 6. Actual US data (thin black lines) and counterfactual paths (thick red lines) generated under a constant inflation target using the unconstrained model with an endogenous inflation target. 

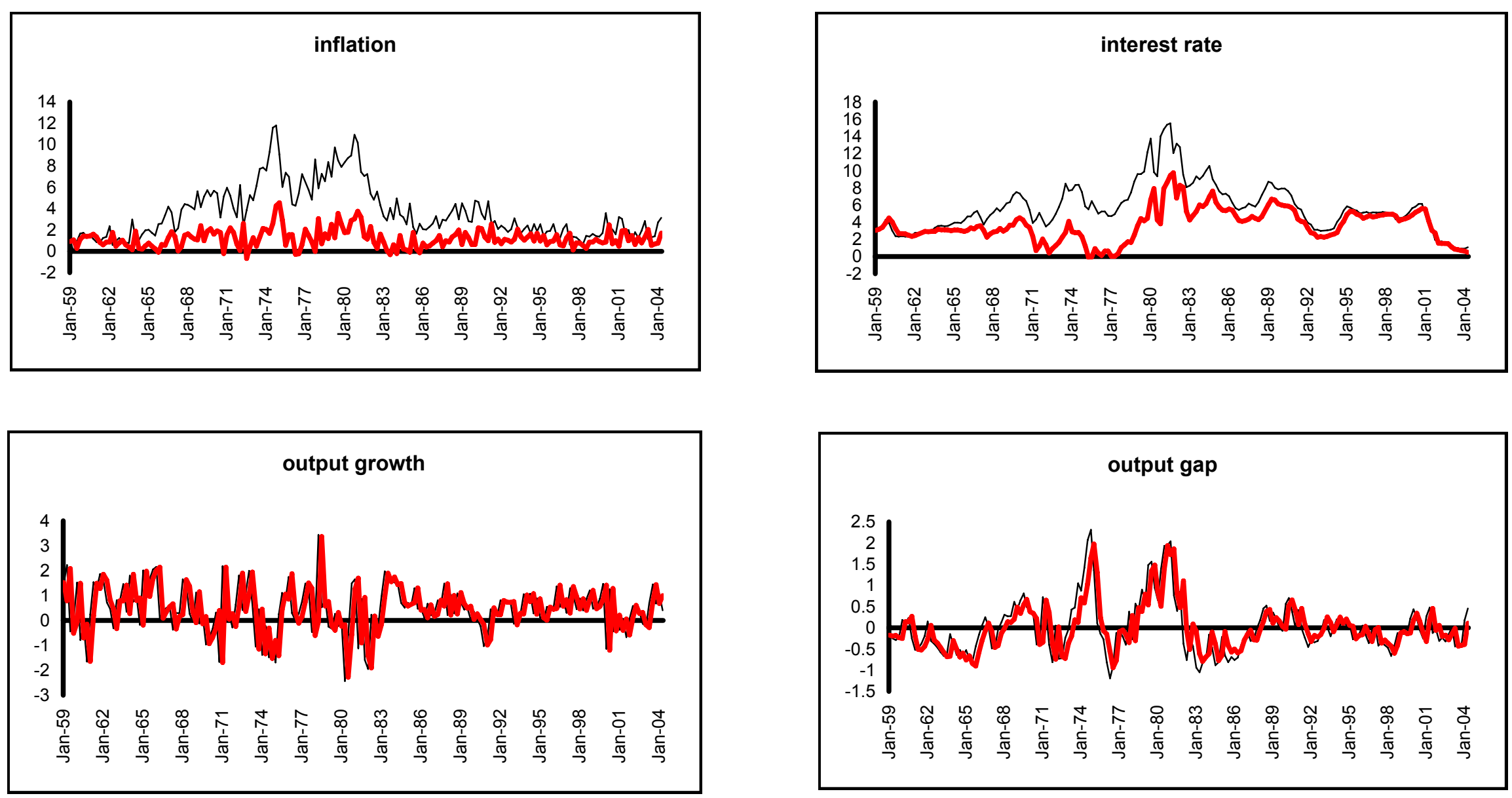

Figure 7. Actual US data (thin black lines) and counterfactual paths (thick red lines) generated under a constant inflation target using the constrained model with an exogenous inflation target. 

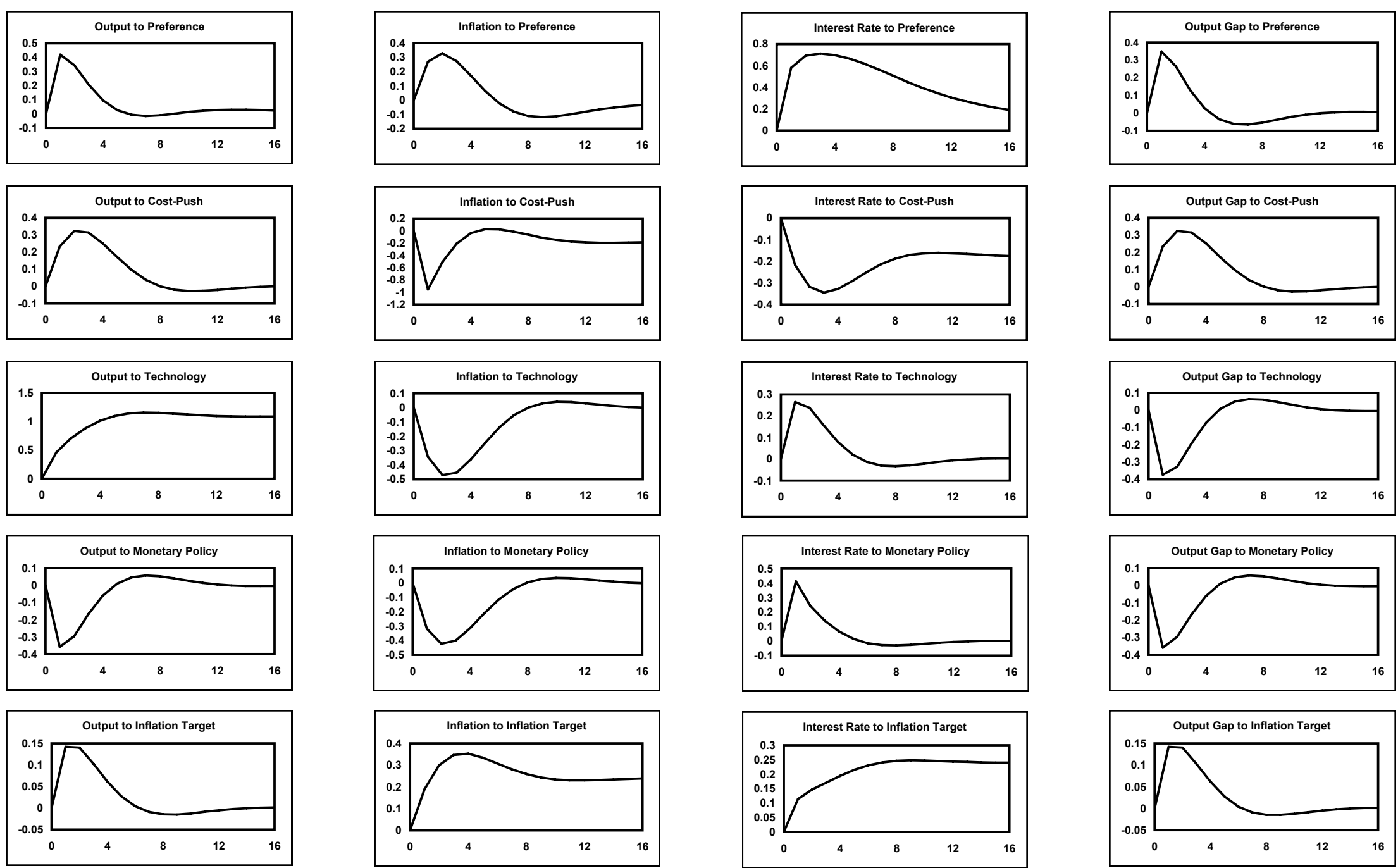

Figure 8. Impulse responses from the constrained model with backward-looking price setting. Each panel shows the percentage-point response of one of the model's variables to a one-standard-deviation shock. The inflation and interest rates are expressed in annualized terms. 


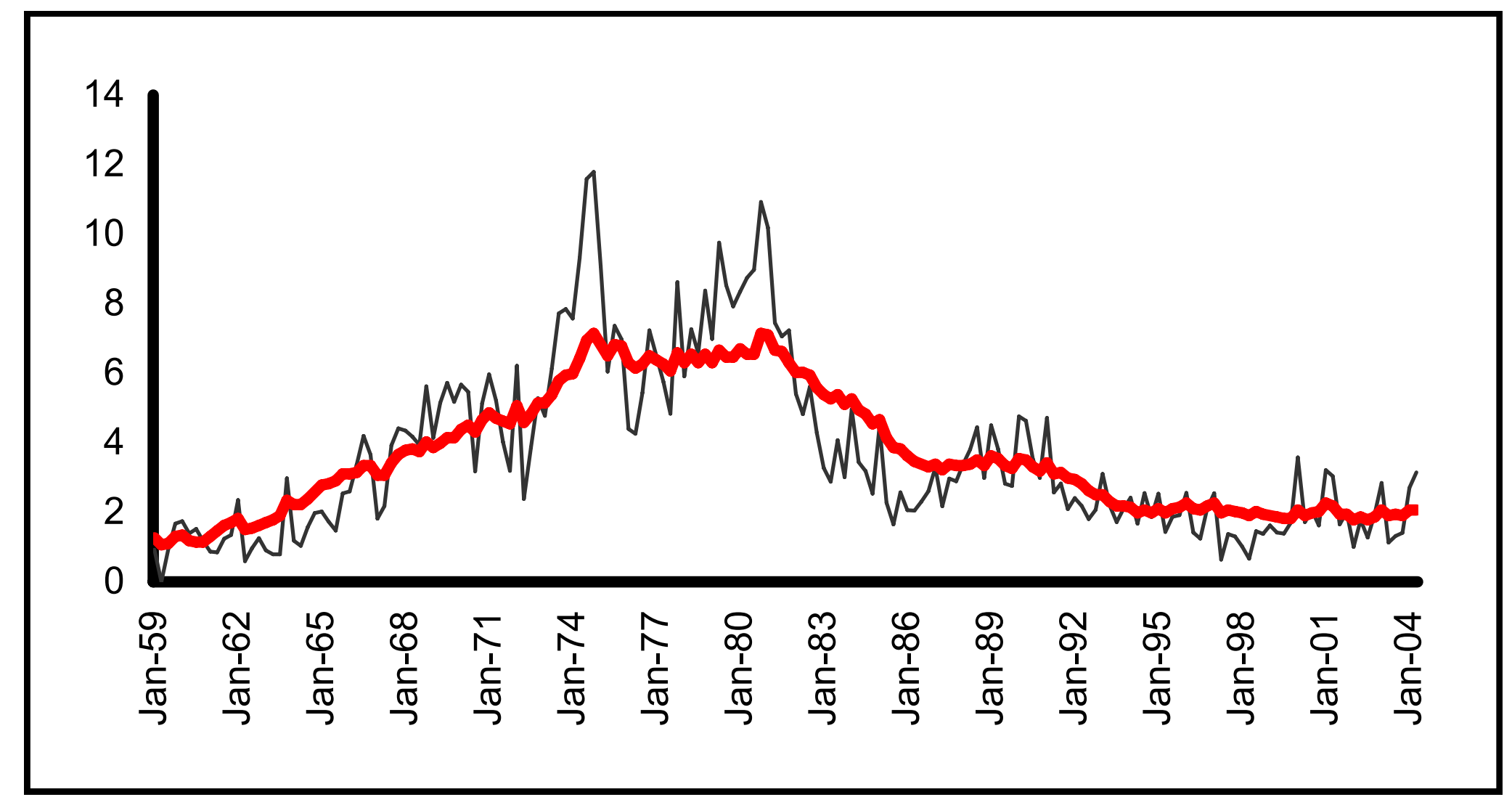

Figure 9. Actual inflation (thin black line) and the Federal Reserve's target (thick red line), as implied by the constrained model with backward-looking price setting. 

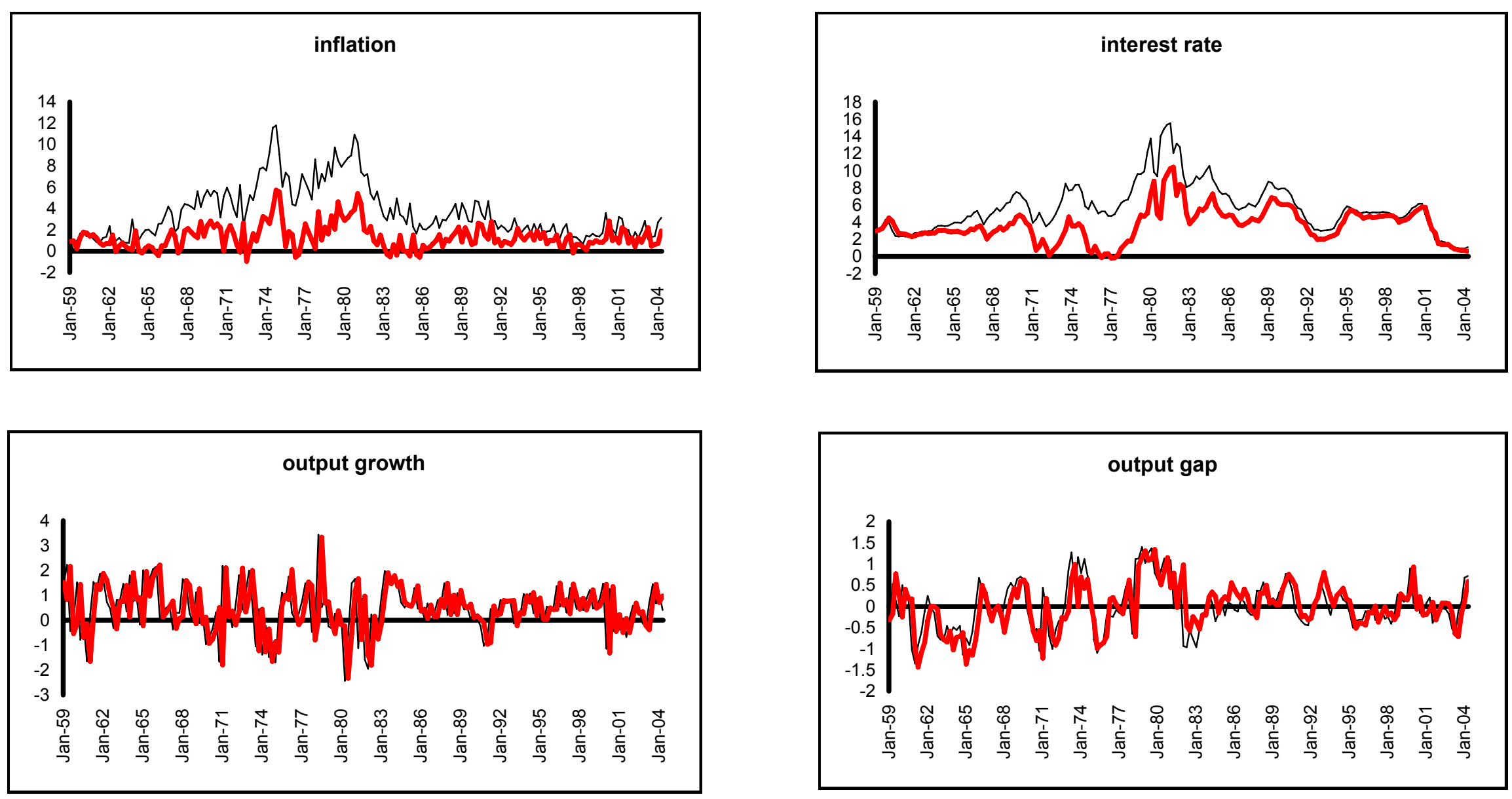

Figure 10. Actual US data (thin black lines) and counterfactual paths (thick red lines) generated under a constant inflation target using the constrained model with backward-looking price setting. 